\title{
Feasible packing of granular materials in discrete-element modelling of cone-penetration testing
}

\author{
Nurhan Ecemis and Paulina Bakunowicz
}

Civil Engineering Department, Izmir Institute of Technology, Izmir, Turkey

\begin{abstract}
This paper explores how the discrete-element method (DEM) was found to play an increasingly important role in cone penetration test (CPT) where continuum-mechanics-based analysis tools are insufficient. We investigated several crucial features of CPT simulations in the two-dimensional DEM. First, the microparameters (stiffness and friction) of discrete material tailored to mimic clean, saturated sand, which is used in cone-penetration tests, were calibrated by curvefitting drained triaxial tests. Then, three series of cone-penetration simulations were conducted to explore (1) top boundary conditions, (2) reasonable size of discrete particles at different initial porosities, and (3) limit initial porosity of the model for a balance between accurate representation and computational efficiency. Further, we compared the cone-penetration resistance obtained in the laboratory and numerical simulations for the range of relative densities.
\end{abstract}

\section{ARTICLE HISTORY}

Received 14 February 2017 Accepted 30 January 2018

\section{KEYWORDS}

Cone-penetration test discrete-element modelling; granular material; triaxial test; porosity; coordination number

\section{Introduction}

The cone-penetration test (CPT) is an in situ test that has gained worldwide attention because it provides a continuous or near-continuous soil profile. Moreover, it is rapid, repeatable, reliable, and cost-effective when compared to other field tests (Lunne et al. 1997, Mayne 2007). A cone mounted at the end of series of rods is pushed into the ground at a constant penetration rate of $2 \mathrm{~cm} / \mathrm{s}$ (ASTM D3441). Meanwhile, the independent parameters, including cone-penetration resistance $\left(q_{\mathrm{c}}\right)$ and friction resistance $\left(f_{\mathrm{s}}\right)$ are measured (Lunne et al. 1997). The interpretation of measured CPT parameters in highly permeable sands essentially relies on empirical or semi-empirical methods (Mayne 2007). These methods include (1) bearing capacity theories by limit plasticity, such as by Meyerhof (1961), Janbu and Senneset (1974), and Durgunoglu and Mitchell (1975a, 1975b); (2) cavity-expansion theories, such as by Baligh (1975, Vesic (1972), Salgado et al. (1997), and $\mathrm{Yu}$ and Mitchell 1998); and (3) steady-state cone-penetration and strain-path methods, such as by Baligh (1985), Houlsby et al. (1985), Teh and Houlsby (1991), and Whittle (1992). Laboratory studies using centrifuge tests (e.g. Bolton and Gui 1993) and calibration-chamber tests (e.g. Houlsby and Hitchmann, 1988, Ghionna and Jamiolkowski 1991) have also been performed to study cone-penetration. Laboratory tests are expensive, and conducting a CPT in the calibration chamber is laborious.

Several researchers have used different advanced constitutive and numerical approaches, such as finiteelement method (FEM) and finite-difference method (FDM), to provide a better insight into the penetration process. Within these numerical methods, one can easily monitor internal parameters that are difficult to measure in the field and laboratory. During the installation of cones, large deformations and strains are observed in the soil both in the calibration chambers and in the field. The CPT deformation effects are complicated due to the complex behaviour of the soil, material nonlinearities, anisotropy, inelasticity, time dependence, frictional response, large-strain contact, and so on (Baligh 1985). This is why continuous remeshing and perfect constitutive modelling are needed during cone penetration in these numerical approaches. By using a complex adjustment process, Susila and Hryciw (2003) found some agreement between physical tests results and predicted CPT results using FEM in sands. Ahmadi et al. (2005) obtained approximately $20 \%$ mean error in CPT results using FDM in sands. Recently, the discrete-element method (DEM) was found to play an increasingly important role in geomechanical problems regarding not only qualitative response but also quantitative compatibility, especially in applications where continuum- 
based modelling techniques are insufficient (Vermeer et al. 2001, Utili and Nova 2008, Bienen et al. 2011, McDowell et al. 2012, Lin and Wu 2012, Butlanska et al. 2014).

DEM has particular benefits over other numerical approaches. It allows the micromechanics of soil to be investigated, such as grain contacts, coordination number $(\mathrm{CN})$, and displacements. DEM-based models can also be examined at the mesoscale and macroscale levels. In comparison with FEM, discrete-element approaches make large displacements between elements easy to simulate. Moreover, DEM outperforms FEM while dealing with discontinuous problems, where FEM becomes computationally inefficient. Realistic DEM simulations require an enormous amount of discs for two-dimensional simulations or spheres for three-dimensional simulations due to the discontinuous medium of the soil. Thus, a balance needs to be reached between realistic simulation and efficiency in computation (Huang and Ma 1994).

Various aspects of the cone-penetration process by combining the physical tests with DEM simulations were studied by many researchers, including Huang and Ma (1994), Calvetti and Nova (2005), Jiang et al. (2006), Kinloch and O'Sullivan (2007), Butlanska et al. (2009), Arroyo et al. (2011), Butlanska et al. (2014), and Ciantia et al. (2016). Huang and Ma (1994) were among the first to apply two-dimensional DEM for the simulation of deep penetration in sand. Their results showed that both the penetration mechanism and soil dilatancy are affected by the loading history of granular materials. Calvetti and Nova (2005) performed twodimensional distinct-element simulations to explore a relationship between micro- and macroparameters that are used to describe the resistance and stiffness of the granular material. Jiang et al. (2006) used a two-dimensional DEM model to study the plane-strain penetration mechanism in a granular material with the focus on the effect of soil-penetrometer interface friction. This research showed complex displacement paths of soil near the penetrometer. Also, Jiang et al. noticed the rotation of principal stresses up to $180^{\circ}$. Arroyo et al. (2011) employed three-dimensional DEM models to simulate CPTs in Ticino sand. They noticed that the cone resistance in the DEM model was affected by the same ratio of the cone to the chamber size, which also affected the laboratory cone-penetration results. In their study, the rotation of the spherical particles was prevented. They did not attempt to investigate the grain crushing, as they assumed that it may have had a secondary influence due to the relatively strong sand specimen. However, Kinloch and O'Sullivan (2007) focused on the failure mechanism of granular soil touching to the penetrometer and observed a consistent trend in the direction of the rotation of particles close to the penetrometer. Particles on the left side of the cone tended to rotate in a clockwise manner, and particles on the right side of the cone tended to rotate in a counterclockwise direction. Moreover, Ciantia et al. (2016) investigated the effect of grain crushing on the CPT tip by using crushable microporous discrete material. They found that the initial estimate of internal porosity variation in particle diameter has an effect on the amount of crushing. Butlanska et al. (2009) studied homogeneity and symmetry in DEM models of the CPT. Numerical results of penetration throughout the depth match fairly well with the experimental ones. A bias towards higher values because of enforced model symmetry was evident, especially for dense deposits. Butlanska et al. (2014) examined the results of CPT simulations at the macroscale, mesoscale, and microscale levels. In their models, they captured the macroscale effects of initial soil density, vertical stress, radial boundary condition, and particle shape on cone penetration. They also highlighted several mesoscale and microscale aspects, such as the radial stress decrease with tip distance, soil entrapment alongside the shaft, and contact-force distribution induced by particle rotation.

Besides many studies, there are still many issues and difficulties that need further assessment in distinct-element simulations - for instance, the effect of mean grain size, discrete material packing (porosity), and $\mathrm{CN}$ on cone resistance. In this study, the discrete-element models were built with commercially available two-dimensional DEM Particle Flow Code, or PFC ${ }^{2-D}$ (Itasca, 2008). The two-dimensional analysis was chosen, as it is less computationally demanding, and there are still some uncertainties in two-dimensional CPT simulations that need to be investigated. It is important to note that, using two-dimensional simulations, only a qualitative compression with the real behaviour of the granular material is possible. Radial and vertical positions of field variables like displacements, strains, stresses, and pore water pressures are crucial problems in the two-dimensional analysis of CPT simulations (Baligh 1985). We attempted to model a two-dimensional plain-strain CPT model to eliminate some of the limitations of two-dimensional DEM penetration modelling.

In this study, at first, calibration of the elastic and plastic microproperties of discrete material was performed by comparing the physical and numerical triaxial test results. Secondly, three CPT simulation series were performed for detailed investigations of several critical features of CPT-DEM modelling in a two- 


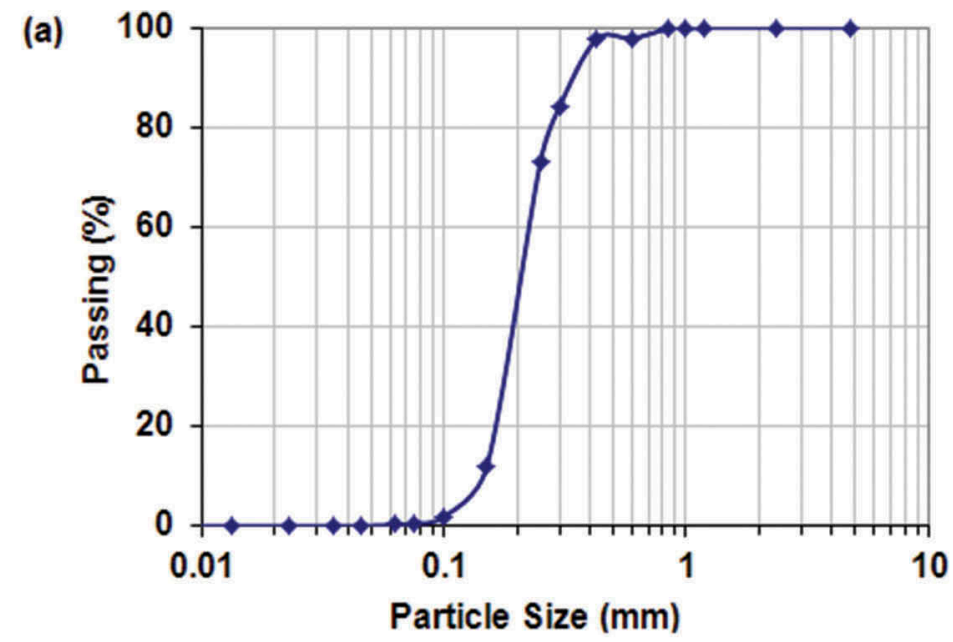

(b)

\begin{tabular}{|cc|}
\hline Parameters & Values \\
\hline $\mathrm{G}_{\mathrm{s}}$ & 2.61 \\
\hline $\mathrm{e}_{\max }$ & 0.79 \\
\hline $\mathrm{e}_{\min }$ & 0.60 \\
\hline $\mathrm{D}_{10}(\mathbf{m m})$ & 0.12 \\
\hline $\mathrm{D}_{30}(\mathbf{m m})$ & 0.18 \\
\hline $\mathrm{D}_{50}(\mathbf{m m})$ & 0.21 \\
\hline $\mathrm{C}_{\mathrm{u}}$ & 1.17 \\
\hline $\mathrm{C}_{\mathrm{c}}$ & 1.29 \\
\hline
\end{tabular}

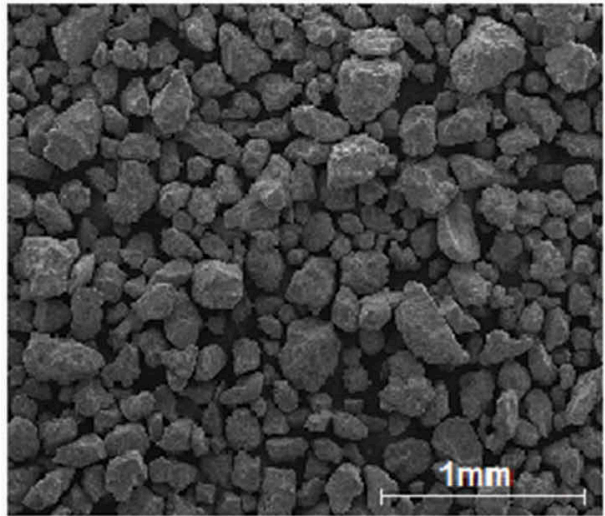

Figure 1. (a) The grain size distribution curve of sand used in the physical CPTs; (b) sand parameters and scanning electron micrograph of the grains.

dimensional environment. CPT simulation series I was performed to investigate (1) the movement effect of the top boundary on particle packing, and (2) reasonable size of grains for a maximum number of contacts between particles and $3.6-\mathrm{cm}$ diameter cone. CPT simulation series II was conducted to determine the satisfying size of spherical grains at different initial porosities. CPT simulation series III was implemented to (1) calibrate the initial porosity of the model by using the results of the CPTs conducted in the laboratory, and (2) investigate the limit porosity of the model for accurate penetration results.

\section{Experimental study}

\subsection{Material}

For testing purposes, we used uniform fine silica sand that can be easily adapted to experimental and numerical research. Its grain-size curve is shown in Figure 1 (a). According to the unified soil-classification system, the soil was defined as poorly graded sand (SP). The sand particles used in the tests were naturally formed subangular sand grains, which were supplied locally. Figure 1(b) shows the sand parameters and particle shape of the sand grains (SEM picture).

\subsection{Physical triaxial tests}

Two consolidated drained (CD) triaxial tests (ASTM D7181-11) were conducted on the sand for calibration of stiffness and friction parameters of DEM model. The loose sand samples (100 $\mathrm{mm}$ x $50 \mathrm{~mm})$ having $30 \%$ relative density were prepared by the tamping method under moist conditions. Samples prepared using the moist-tamping technique usually demonstrate strain-softening behaviour because of their integral high-void ratios (Vaid and Sivathayalan 2000). Wood et al. (2008) concluded that wet-deposition methods seem to point out a more volumetrically dilatant or stable response, while dry methods appeared to signal a more contractive or unstable behaviour. More details about the triaxial tests can be found at Bakunowicz (2014). The stress-strain behaviour of the soil for the isotropic stresses of 100 

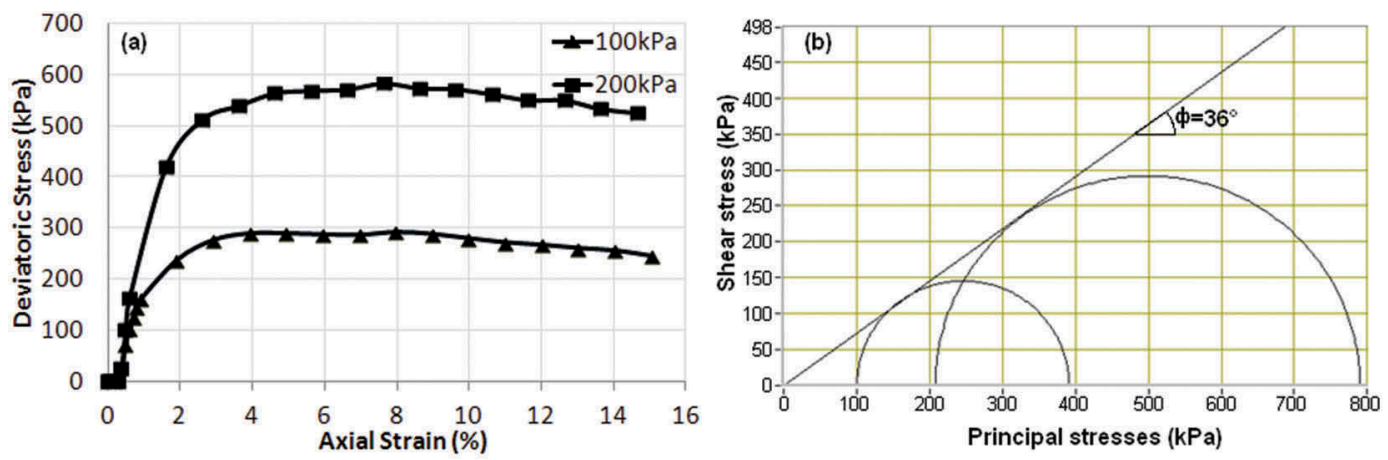

Figure 2. Results of CD triaxial tests, confined at 100 and $200 \mathrm{kPa}$, for sand having a relative density of $30 \%$.

and $200 \mathrm{kPa}$ is shown in Figure 2(a). The friction angle $(\phi)$ of this sand was determined from the drained triaxial test data as shown in Figure 2(b). It was derived from the Mohr-Coulomb failure criterion and equated to $36^{\circ}$. This friction angle value is consistent with the value measured in similar soils Koloski et al. (1989).

\subsection{Physical CPTs}

A total of six sand deposits, each of which had a width of $45 \mathrm{~cm}$, a length of $163 \mathrm{~cm}$, and a height of $150 \mathrm{~cm}$, were prepared inside the box by hydraulic filling method (Whitman 1970). By using the one degree of freedom shaking table, each of these six soil deposits were subjected to three subsequent shaking tests (Ecemis 2013). After each shaking test, CPTs were performed throughout the depth of the soil. As shown in Figure 3(a-b), the cone-penetration system with a maximum plumper cylinder capacity of $50 \mathrm{kN}$ and stroke length of $1 \mathrm{~m}$ is used to advance $60^{\circ}$ tapered, $10 \mathrm{~cm}^{2}$ tip area cone (diameter of $3.6 \mathrm{~cm}$ ) into the soil at one location at a constant penetration speed of $2 \mathrm{~cm} / \mathrm{s}$ (ASTM D3441). The nova acoustic CPT device which can measure the cone-penetration resistance $\left(q_{c}\right)$ and friction resistance $\left(f_{s}\right)$ values with the depth of the soil was manufactured by Geotech Inc., Sweden. (a)

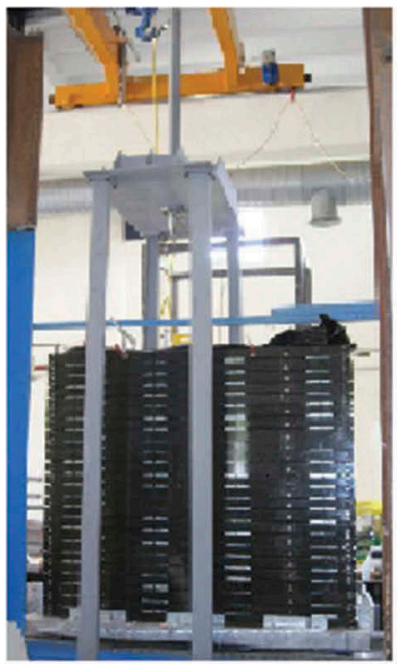

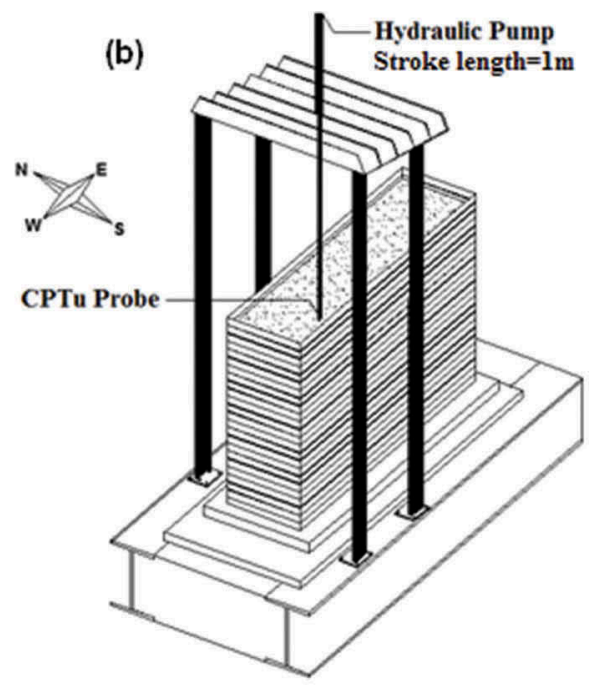

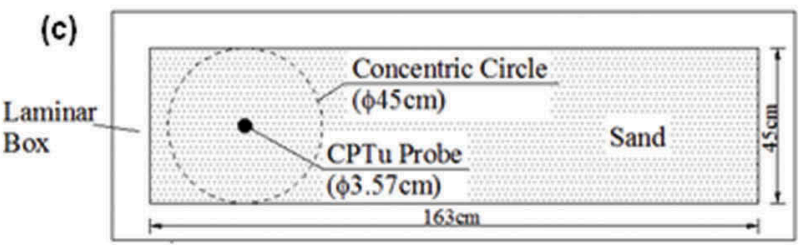

Figure 3. (a) Schematic view of the cone-penetration system; (b) photo of the CPT system; and (c) horizontal location of cone penetration in the soil. 
The relative density along the soil depth was indirectly determined from the measured cone-penetration resistance by using the empirical relationship given by Jamiolkowski et al. (1985).

$$
D_{\mathrm{r}}=-98+66 * \log _{10}\left(\frac{q_{\mathrm{c}}}{\sqrt{\sigma_{\mathrm{vo}}^{\prime}}}\right)
$$

where $D_{\mathrm{r}}$ is the relative density in percentage, $\sigma_{\mathrm{vo}}$ ' is the effective initial vertical stress in $\mathrm{kPa}$, and $q_{\mathrm{c}}$ is the measured cone-penetration resistance in $\mathrm{kPa}$. Bolton and Gui (1993) stated that, for a particular depth, Equation (1) overestimates and underestimates the $D_{\mathrm{r}}$ values, by approximately $10 \%$ and $20 \%$, respectively. To verify the relative density estimated from the empirical relation, the initial relative density of the soil along its depth was directly measured by cylindrical steel buckets. They were placed inside the box at four different depths during the hydraulic filling and then removed when the buckets were filled with the sample. The initial relative densities of the prepared sample were $15-40 \%$ with an average for the whole deposit close to $25 \%$. The relative densities obtained using the steel buckets ranged from $18 \%$ to $38 \%$ and were reasonably consistent with the relative density range estimated from Equation (1). These values are consistent with the relative density intervals measured immediately after deposition in clean-sand hydraulic fills (Whitman 1970, Poulos and Hed 1973, Mitchell et al. 1999, Thevanayagam et al. 2009).

A total of 18 CPTs were conducted in the laboratory at different relative densities from $25 \%$ to $70 \%$. To exemplify, Figure $4(\mathrm{a}-\mathrm{d})$ display four $q_{\mathrm{c}}$ profiles and corresponding trend-curves obtained from CPTs. Cone penetrations were conducted at sand deposits of $25 \%$, $45 \%, 56 \%$, and $70 \%$ average relative density. As shown in the figure, limit cone-penetration resistance, defined as $\left(q_{\mathrm{c}}\right)_{\text {limit }}$, were extracted at a depth of $1 \mathrm{~m}$ by using the trend-curves. It is clear from the figure that an increase in relative density increased the limit cone resistance. The cone-penetration resistance was also estimated from the friction angle that was obtained from the triaxial tests. By using the relationship given by Robertson and Campanella (1983), for $36^{\circ}$ friction angle, cone-penetration resistance was determined less than $1 \mathrm{MPa}$. As illustrated in Figure 4, the $q_{\mathrm{c}}$ values throughout the sand were determined less than $1 \mathrm{MPa}$, which is consistent with the cone-penetration resistance values estimated by Robertson and Campanella (1983).

For the tested soil material with known limit void ratios $\left(e_{\max }=0.79, e_{\min }=0.6\right)$, the porosity of the soil, $n_{\text {soil }}$, ranged from 0.40 to 0.43 . Figure 5 shows the relationship between the porosity of the soil and limit cone-penetration $\left(q_{\mathrm{c}}\right)_{\text {limit }}$ values. The relationship between the porosity of the sand and $\left(q_{\mathrm{c}}\right)_{\text {limit }}$ was given as follows:

$$
n_{\text {soil }}=0.4-0.02 \ln \left(q_{\mathrm{c}}\right)_{\text {limit }}
$$

where $n_{\text {soil }}$ is in decimal and $\left(q_{\mathrm{c}}\right)_{\text {limit }}$ in MPa. These porosity ranges were later used in a calibration part of the DEM model.

The physical CPT results can be affected by the sample/cone size and boundary conditions. Several researchers (Parkin and Lunne 1982, Phillips and Valsangkar 1987, Renzi et al. 1994) have observed the effects of boundary conditions on CPT data and have proposed a diameter ratio, defined as $R_{\mathrm{d}}$, to decide whether boundary effects on the CPT measurements are significant. $R_{\mathrm{d}}$ is identified as the ratio of sample

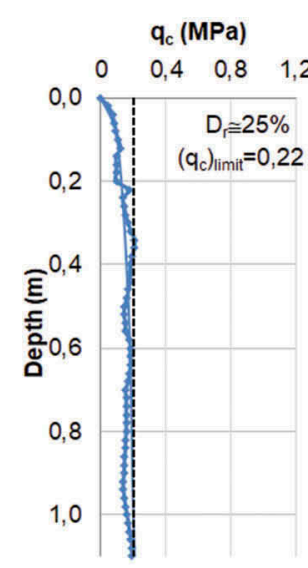

(a)

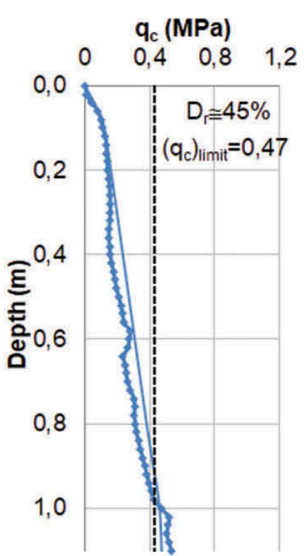

(b)

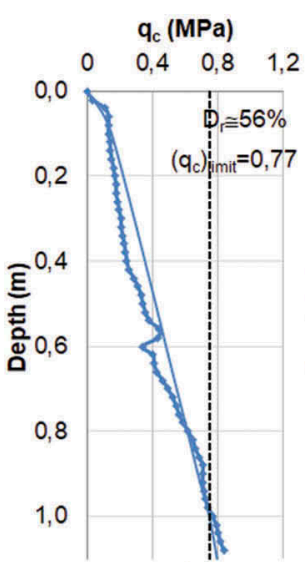

(c)

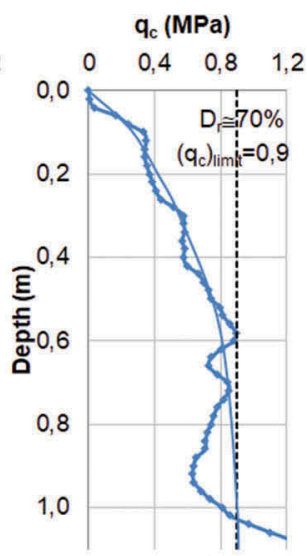

(d)

Figure 4. $q_{c}$ profiles and corresponding trend-curves obtained from sand deposits for average relative density of (a) $25 \%$, (b) $45 \%$, (c) $56 \%$, and (d) $70 \%$. 


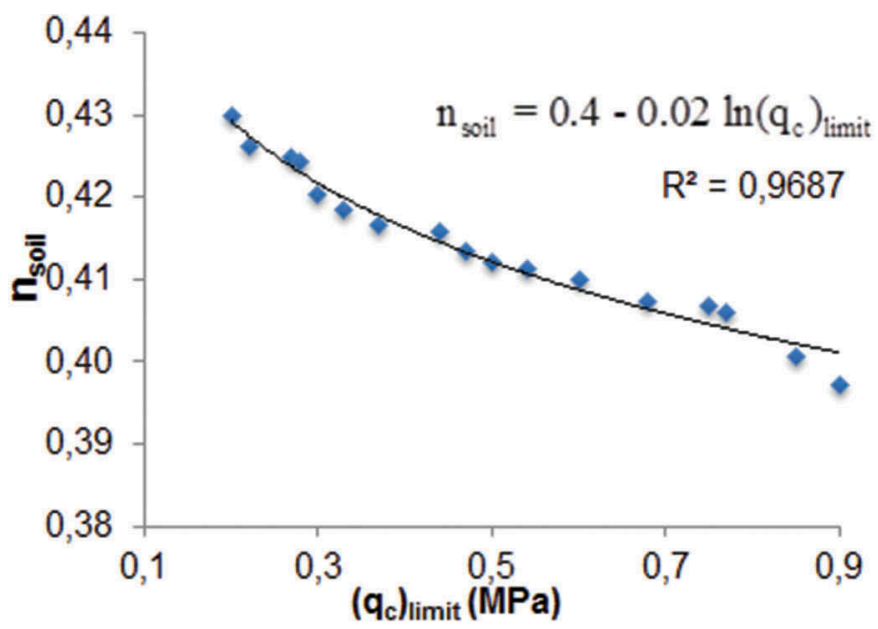

Figure 5. Relationship between porosity of soil and limit cone-penetration resistance from physical CPTs in the box.

diameter to cone diameter. Parkin and Lunne (1982) stated that the side-boundary effects depend on the relative density of the sand. For loose sand with a relative density on the order of $30 \%$, the side-boundary effects are negligible (Parkin and Lunne 1982). Phillips and Valsangkar (1987) reported that for dense sands with a relative density on the order of $85 \%$, the sideboundary effects are not significant, even when the probe is located at a distance from the wall corresponding to $R_{\mathrm{d}}=5$. Renzi et al. (1994) prepared specimens at high densities in a cylindrical container and showed no apparent increase in cone-penetration resistance for tests conducted at $R_{\mathrm{d}}=11$ as compared to $R_{\mathrm{d}}=22$. In this study, cone penetrations were performed along one concentric circle as shown in Figure 3(c), with the outer circle being $45 \mathrm{~cm}$ from the laminar box edge. Using $45 \mathrm{~cm}$ as the distance to the wall gave $R_{\mathrm{d}}$ value 13 for the cone that had a diameter of $3.6 \mathrm{~cm}$. The effects of the boundary conditions on the recorded CPT data were satisfactory when $R_{\mathrm{d}}$ values reported in the literature were considered. More details about the physical modelling, shaking-table system, and the reliability of the measured data can be found at Ecemis (2013) and Ecemis et al. (2015).

\section{Numerical study}

\subsection{Discrete element method}

The DEM, also called a distinct-element method is increasingly used to study geotechnical engineering problems particularly in cases where continuum-based modelling techniques are poorly adapted. In this study, the cone-penetration simulations were performed by DEM using two-dimensional Particle Flow Code PFC $^{2-D}$ (Itasca Consulting Group: PFC2D 2008) for its ability to provide micromechanical insight into the behaviour of granular materials and cone-penetration resistance. This method computes the stresses and displacements in a volume containing a large number of spherical particles that are interacting in a dynamic process. To simulate the influence of non-spherical element profiles, we did not allow particle rotations. Ting et al. (1989) indicated that avoiding particle rotation is important to achieve accurate friction angles with spherical particles.

The elasto-plastic discrete particle contact criteria was assumed in the model. The constitutive behaviour of soil material was performed by associating a linear contact model with each contact. The elastic microproperties of discrete material were defined by normal stiffness $\left(k_{\mathrm{n}}\right)$ and tangential stiffness $\left(k_{\mathrm{s}}\right)$. The plastic microproperties were defined by the interparticle friction coefficient $\left(\mu_{\mathrm{p}}\right)$. The radius-expansion method (Cundall and Strack 1979) was used to generate an assembly with specified uniform-sized particles, porosity, and sample size. Implementing uniform diameter of discrete material offers the very practical advantage of simplifying numerical DEM simulations and shortening computation time.

\subsection{Calibration of contact model parameters by biaxial test simulations}

The contact model parameters of the granular material, used in the numerical simulations of CPTs, were calibrated by comparing the physical triaxial test and simulated biaxial test results. Isotropically compressed drained triaxial test sample confined at $100 \mathrm{kPa}$ and formed with $30 \%$ relative density was used to calibrate density $(\rho)$, normal stiffness $\left(k_{\mathrm{n}}\right)$, tangential stiffness $\left(k_{\mathrm{s}}\right)$, and 


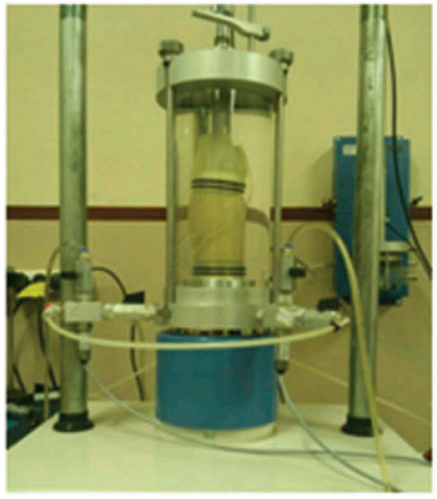

Triaxial test

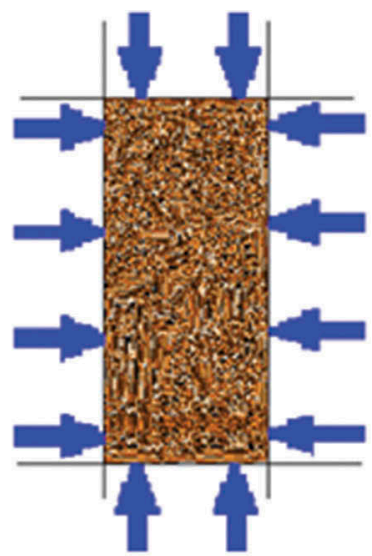

DEM Simulation

\begin{tabular}{|l|l|l|}
\hline Variable (unit) & $\begin{array}{l}\text { Triaxial } \\
\text { test }\end{array}$ & $\begin{array}{l}\text { DEM } \\
\text { simulations }\end{array}$ \\
\hline Chamber length $(\mathrm{mm})$ & 100 & 100 \\
\hline Chamber width $(\mathrm{mm})$ & 50 & 50 \\
\hline Particle mean size, $\mathrm{D}_{50}(\mathrm{~mm})$ & 0,21 & 1 \\
\hline
\end{tabular}

Figure 6. Geometrical characteristics of physical triaxial test and DEM simulation.

interparticle friction coefficient $\left(\mu_{\mathrm{p}}\right)$. We implemented the inverse modelling technique with unknown microproperties of discrete material (Itasca Consulting Group: PFC2D 2008). This technique is based on running multiple numerical simulations with different input parameters to match the laboratory test results.

As shown in Figure 6, the initial dimensions of the physical and numerical triaxial cells were $100 \mathrm{~mm}$ by $50 \mathrm{~mm}$ (height $\times$ width); however, the discrete material was scaled and simplified. Considering the nature of the tested soil, the discrete particles were modelled as a group of uniformly sized discs (of unit thickness) with 1-mm diameter. The diameter of discrete particles was five times larger than the $D_{50}$ of the tested sand. The ratio of discrete particle diameter to chamber width in biaxial tests was $1 / 50$.

Kruyt (1993) suggested the sufficient number of particles to obtain meaningful biaxial test results is more than a thousand elements. Following the chosen particle-generation approach, assembly of 5300 particles was created. The initial sample porosity was set to 0.17 , which is the maximum limit value for particles to exchange contact forces (Utili and Nova 2008).

A rectangular cell, which mimicked the triaxial cell, was constructed of four rigid, frictionless walls. Throughout the loading process, the confining pressure of $100 \mathrm{kPa}$ was maintained by adjusting the lateral-wall velocities using a numerical servomechanism (Itasca Consulting Group: PFC2D 2008). All stresses were calculated by taking the average wall forces divided by appropriate areas. Strains in both $X$ and $Y$ directions were computed using the equation given below:

$$
\varepsilon=\frac{L-L_{0}}{0.5\left(L+L_{0}\right)}
$$

Here, $L_{\mathrm{o}}$ is the initial sample length, and $L$ is the current specimen length in the corresponding direction.

The mean confining stress $\left(\sigma_{\mathrm{c}}\right)$ and axial deviatoric stress $\left(\sigma_{\mathrm{d}}\right)$ along with axial strain $\left(\varepsilon_{\mathrm{a}}\right)$ and volumetric strain $\left(\varepsilon_{\mathrm{v}}\right)$ were recorded during the DEM simulations. Figure 7(a) shows the comparison between $\sigma_{\mathrm{d}}$ and $\varepsilon_{\mathrm{a}}$ obtained from the DEM biaxial test simulations and the laboratory tests with a confining pressure of 100 $\mathrm{kPa}$ and relative density of $30 \%$. The closest match between the experimental and the two-dimensional DEM results was obtained with input parameters given in Table 1. As shown in the figure, from the laboratory experiments, the soil reached a peak stress at around $300 \mathrm{kPa}$, which was same as the DEM simulation results. However, the elastic modulus from the analysis did not completely reflect the actual testing results. The initial tangent modulus $(E)_{\text {in }}$, and secant modulus $(E)_{\text {sec }}$, were calculated from the given stressstrain curves for the initial confining pressure of 100 $\mathrm{kPa} .(E)_{\sec }$ that varies over stress ranges was calculated from zero deviatoric stress up to $1 / 2$ or $1 / 3$ of the peak 
(a)

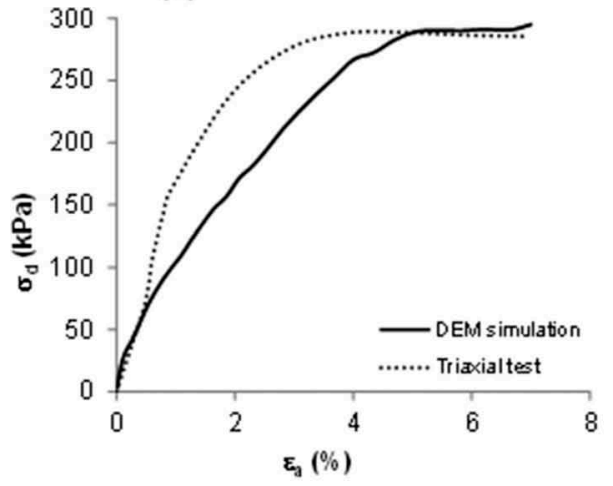

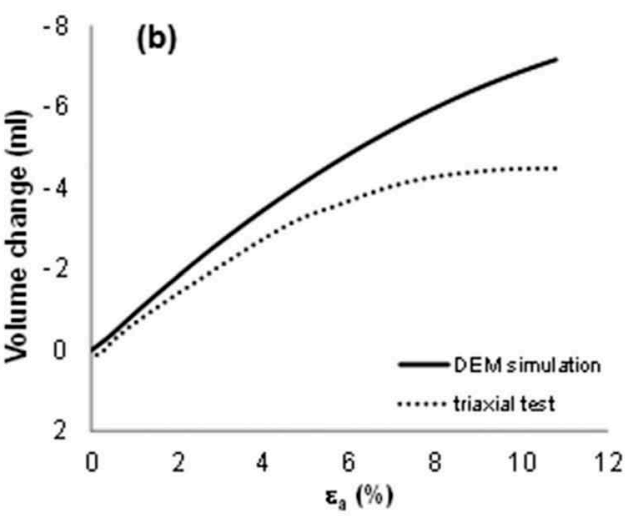

Figure 7. Calibration of DEM material parameters with triaxial tests conducted on the loose sand for $D_{\mathrm{r}}=30 \%$ and confining stress of $100 \mathrm{kPa}$. The relationship between (a) deviatoric stress-axial strain, and (b) volume change-axial strain.

Table 1. Properties of discrete material for simulations of granular deposit.

\begin{tabular}{ll}
\hline Parameter & Value \\
\hline Density, $\rho\left(\mathrm{kg} / \mathrm{m}^{3}\right)$ & 2650 \\
Normal stiffness, $\mathrm{k}_{\mathrm{n}}(\mathrm{N} / \mathrm{m})$ & $6 \times 10^{6}$ \\
Tangent stiffness, $\mathrm{k}_{\mathrm{s}}(\mathrm{N} / \mathrm{m})$ & $1 \times 10^{6}$ \\
Stiffness ratio, $a\left(\mathrm{k}_{\mathrm{s}} / \mathrm{k}_{\mathrm{n}}\right)$ & 0.17 \\
Inter-particle friction coefficient, $\mu_{\rho}$ & 1.0 \\
\hline
\end{tabular}

deviatoric stress at which significant failure had occurred (Lambe and Whitman 1969). At initial axial strain, the deviatoric stress obtained from DEM simulations was $70 \mathrm{kPa}$ higher than the laboratory test results. The $(E)_{\sec }$ for $1 / 2$ peak of deviatoric stress for laboratory and DEM results was very close -7.20 and 6.70 MPa, respectively. However, for $1 / 3$ peak of deviatoric stress, the $(E)_{\mathrm{sec}}$ obtained from the laboratory tests and simulations were 10.40 and $7.60 \mathrm{MPa}$, respectively. From $4.5 \%$ to $9.5 \%$ of axial strain, the results of deviatoric stress were same for both analysis and experiments. At two-dimensional DEM simulations, secant modulus can be affected by interparticle friction and porosity (Calvetti and Nova 2005). Moreover, the studies of Sitharam and Nimbkar (2000) indicate that different gradations and minimum grain size affect the arrangement of particles which can make the results of biaxial simulations different under identical loading conditions.

The change of volume by axial strain between laboratory tests and analysis are shown in Figure 7(b). The tested sample was loose sand that needed to decrease in volume while shearing. Stress-strain curve and volume change behaviour from both numerical and experimental tests confirmed this. At each $\varepsilon_{\mathrm{a}}$ values, the volume changes from the DEM were larger than those obtained in the laboratory experiments. This could be due to the high interparticle friction coefficient. Based on studies on the effect of interparticle friction on the overall sample dilation, Geng (2010) observed an increase in volumetric dilation with an increase in friction coefficient. It also needs to be taken into account that biaxial tests were performed in a two-dimensional environment, in contrary to real three-dimensional conditions. The topic of volume change is much more complex and requires multiple physical testing and numerical analyses to determine a critical void ratio of the tested soil, therefore necessitating different evaluation methods, which is beyond the scope of this paper.

\subsection{CPT simulations}

Total of three CPT simulation series were performed for detailed investigations of top boundary conditions, size of discrete particle size, and limit initial porosity for accurate cone-tip resistance. In all of these simulations, the cone penetrated in the middle of the box with a penetration velocity of $2 \mathrm{~cm} / \mathrm{s}$. The calculation cycle of cone penetration was determined as a time-stepping algorithm that consisted of the repeated application of the law of motion to each particle and a force-displacement law to each contact. The cone-tip angle was $60^{\circ}$. The cone, sample, and particle sizes needed for the system to build each of the CPT-DEM test series are listed in Table 2. During all CPT simulations, the measured quantities (porosity and $\mathrm{CN}$ ) were obtained within the specified circle that was defined as a representative element area (REA).

The cone and box walls were built by means of the wall-logic algorithm with normal $k_{\mathrm{n}}$ and tangent stiffness $k_{\mathrm{s}}$. The cone had actual $k_{\mathrm{n}}$ and $k_{\mathrm{s}}$ values of $2 \times 10^{5}$ $\mathrm{MPa}$. The box walls had normal and tangential stiffness values of 6 and $1 \mathrm{MPa}$, respectively. The friction coefficient $(\mu)$ between the particle and the cone was equal to the interparticle friction coefficient of 1 . The box walls 
Table 2. Summary of geometrical features in CPT simulation series.

\begin{tabular}{|c|c|c|c|c|c|c|c|c|c|c|}
\hline $\begin{array}{l}\text { CPT } \\
\text { Simulation } \\
\text { Series }\end{array}$ & Sample width, B $(\mathrm{cm})$ & Sample height, $\mathrm{H}(\mathrm{cm})$ & Test No. & $\mathrm{D}(\mathrm{cm})$ & $\mathrm{d}(\mathrm{cm})$ & $\mathrm{n}_{\mathrm{DM}}$ & $\mathrm{R}_{\mathrm{d}}$ & $n_{p}$ & c & $\mathrm{R}_{\mathrm{C}}$ \\
\hline \multirow[t]{6}{*}{ I } & 200 & 155 & Test 1 & 3,0 & 2 & 0,10 & 66,7 & 1,5 & 4,0 & 1,33 \\
\hline & & & Test 2 & 3,6 & 2 & 0,10 & 55,6 & 1,8 & 4,0 & 1,11 \\
\hline & & & Test 3 & 4,0 & 2 & 0,10 & 50,0 & 2,0 & 5,0 & 1,25 \\
\hline & & & Test 4 & 5,0 & 2 & 0,10 & 40,0 & 2,5 & 6,0 & 1,20 \\
\hline & & & Test 5 & 6,0 & 2 & 0,10 & 33,3 & 3,0 & 9,0 & 1,50 \\
\hline & & & Test 6 & 10,0 & 2 & 0,10 & 20,0 & 5,0 & 13,0 & 1,30 \\
\hline \multirow[t]{24}{*}{ II } & 200 & 155 & Test 7 & 3,6 & 0,8 & 0,11 & 55,6 & 4,5 & & \\
\hline & & & Test 8 & 3,6 & 0,8 & 0,12 & 55,6 & 4,5 & & \\
\hline & & & Test 9 & 3,6 & 0,8 & 0,13 & 55,6 & 4,5 & & \\
\hline & & & Test 10 & 3,6 & 0,8 & 0,14 & 55,6 & 4,5 & & \\
\hline & & & Test 11 & 3,6 & 0,8 & 0,15 & 55,6 & 4,5 & & \\
\hline & & & Test 12 & 3,6 & 0,8 & 0,16 & 55,6 & 4,5 & & \\
\hline & & & Test 13 & 3,6 & 1 & 0,11 & 55,6 & 3,6 & & \\
\hline & & & Test 14 & 3,6 & 1 & 0,12 & 55,6 & 3,6 & & \\
\hline & & & Test 15 & 3,6 & 1 & 0,13 & 55,6 & 3,6 & & \\
\hline & & & Test 16 & 3,6 & 1 & 0,14 & 55,6 & 3,6 & & \\
\hline & & & Test 17 & 3,6 & 1 & 0,15 & 55,6 & 3,6 & & \\
\hline & & & Test 18 & 3,6 & 1 & 0,16 & 55,6 & 3,6 & - & - \\
\hline & & & Test 19 & 3,6 & 1,5 & 0,11 & 55,6 & 2,4 & & \\
\hline & & & Test 20 & 3,6 & 1,5 & 0,12 & 55,6 & 2,4 & & \\
\hline & & & Test 21 & 3,6 & 1,5 & 0,13 & 55,6 & 2,4 & & \\
\hline & & & Test 22 & 3,6 & 1,5 & 0,14 & 55,6 & 2,4 & & \\
\hline & & & Test 23 & 3,6 & 1,5 & 0,15 & 55,6 & 2,4 & & \\
\hline & & & Test 24 & 3,6 & 1,5 & 0,16 & 55,6 & 2,4 & & \\
\hline & & & Test 25 & 3,6 & 2 & 0,11 & 55,6 & 1,8 & & \\
\hline & & & Test 26 & 3,6 & 2 & 0,12 & 55,6 & 1,8 & & \\
\hline & & & Test 27 & 3,6 & 2 & 0,13 & 55,6 & 1,8 & & \\
\hline & & & Test 28 & 3,6 & 2 & 0,14 & 55,6 & 1,8 & & \\
\hline & & & Test 29 & 3,6 & 2 & 0,15 & 55,6 & 1,8 & & \\
\hline & & & Test 30 & 3,6 & 2 & 0,16 & 55,6 & 1,8 & & \\
\hline \multirow[t]{8}{*}{111} & 70 & 120 & Test 31 & 3,6 & 1 & 0,09 & 19,4 & 3,6 & - & - \\
\hline & & & Test 32 & 3,6 & 1 & 0,10 & 19,4 & 3,6 & & \\
\hline & & & Test 33 & 3,6 & 1 & 0,11 & 19,4 & 3,6 & & \\
\hline & & & Test 34 & 3,6 & 1 & 0,12 & 19,4 & 3,6 & & \\
\hline & & & Test 35 & 3,6 & 1 & 0,13 & 19,4 & 3,6 & & \\
\hline & & & Test 36 & 3,6 & 1 & 0,14 & 19,4 & 3,6 & & \\
\hline & & & Test 37 & 3,6 & 1 & 0,15 & 19,4 & 3,6 & & \\
\hline & & & Test 38 & 3,6 & 1 & 0,16 & 19,4 & 3,6 & & \\
\hline
\end{tabular}

D:cone diameter, $d$ : diameter of discrete particle, $n_{D M}$ : porosity of discrete model: $R_{d}=B / D, n_{p}$ : ratio of cone diameter to mean particle size; $C$ : number of particle contacts with cone surface $R_{C}=C / D$.

were rigid and frictionless $(\mu=0)$. The constant horizontal stress of $100 \mathrm{kPa}$ was maintained at the side walls (servo-controlled walls). The displacement at the bottom of the box was not allowed (fixed-boundary).

To decide whether sample size at each of the CPT simulations was significant, the diameter ratio, $R_{\mathrm{d}}$, was checked. $R_{\mathrm{d}}$ is identified as the ratio of soil deposit diameter to cone diameter. The calculated $R_{\mathrm{d}}$ values for each size of the cone are listed in Table 2. Several researchers observed the effects of the sample dimensions on cone-penetration data obtained from the twodimensional DEM simulations (Ma 1994, Calvetti and Nova 2005, Jiang et al. 2006). Ma (1994); Calvetti and Nova (2005); and Jiang et al. (2006) used $R_{\mathrm{d}}$ values as 16,12 , and 17.5 , respectively. When two-dimensional DEM studies related to CPTs in the literature are considered, the smallest $R_{\mathrm{d}}$ value of 19.4 utilised in these simulations was satisfactory. $n_{\mathrm{p}}$ notation given in Table 2 is defined as the ratio of cone diameter to discrete particle size. The $n_{\mathrm{p}}$ value influenced noise of the raw penetration data (Butlanska et al. 2014). With a decrease in $n_{\mathrm{p}}$ value, the raw penetration data throughout the depth can become very jagged. In this study, $n_{\mathrm{p}}$ values vary from 1.5 to 5. Using $1 \mathrm{~cm}$ as the mean particle size gives $n_{\mathrm{p}}$ value 3.6 for the cone that had a diameter of $3.6 \mathrm{~cm}$. This value is similar to the one employed by Arroyo et al. (2011). More details about the numerical modelling and CPT simulations can be found at Bakunowicz (2014) and Bakunowicz and Ecemis (2014).

\subsubsection{Test series I and II}

A suitable top boundary and scaling for discrete particle size is necessary for a balance between accurate representation and computational efficiency. CPT simulation series I was performed to investigate (1) 


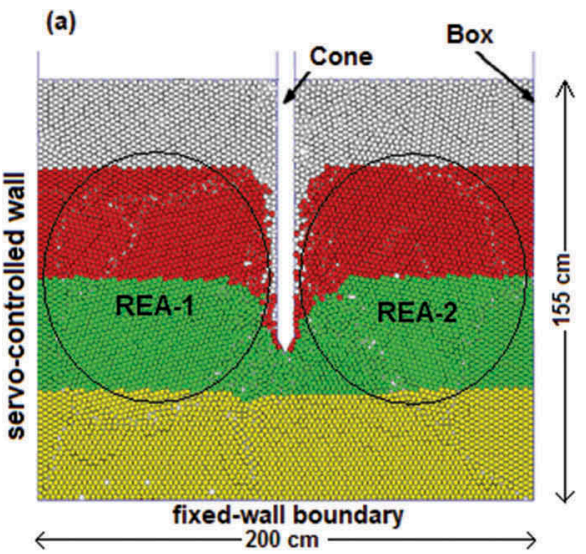

(b)

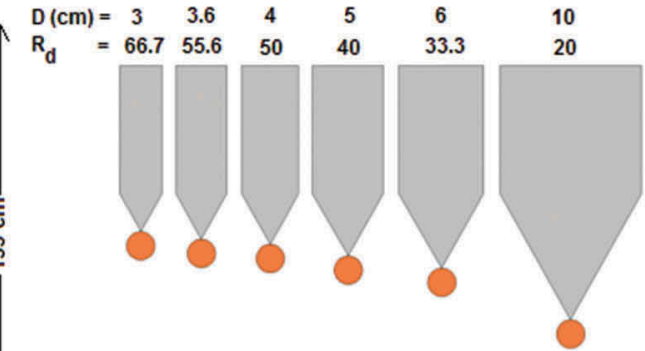

$\mathrm{d}=2 \mathrm{~cm}$

discrete particle

Figure 8. The view of (a) DEM-CPT system model components used in test series I and II, and (b) cone dimensions and discrete particle size used in CPT simulation series I

movement effect of the top boundary on particle packing, and (2) reasonable size of spherical grains for a maximum number of contacts between particles and 3.6- $\mathrm{cm}$ diameter cone. CPT simulation series II was conducted to determine the satisfying size of spherical grains at different initial porosities. The view of the DEM-CPT system model components including the cone, sample, and side/bottom boundary conditions, used in test series I and II, is shown in Figure 8(a). The height of the sample built in the DEM simulations was set to $155 \mathrm{~cm}$ and width set to $200 \mathrm{~cm}$.

3.3.1.1. Effect of top boundary on porosity. Cones with six different diameters, from 3 to $10 \mathrm{~cm}$, were penetrated into the discrete model. Figure $8(\mathrm{~b})$ shows the cone dimensions used in CPT simulation series I. The soil assembly was built with uniform particles of 2$\mathrm{cm}$ diameter and constant initial porosity of 0.1 . Before and after the cone penetrated into the discrete material, up to $1-\mathrm{m}$ depth, the average porosity was obtained from REAs. As shown in Figure 8(a), two REAs were positioned outside of the cone (in the discrete material) to observe porosity changes accurately. The top and bottom boundary effects on the measured quantities were eliminated by positioning the circles in the middle depth of the discrete material. Thus, REAs were created with a maximum possible radius of $45 \mathrm{~cm}$. The circle on the left side of the cone was labelled as REA-1 and the one on the right REA-2.

The decrease in average porosity with fixed and servo-controlled top boundary is given in Figure 9. With the application of a fixed wall on the top, porosity decreased radically for each CPT conducted at the same cone diameter. To eliminate the large porosity reduction and to prevent the particles from random trajectories after they contacted the cone, the servocontrolled top boundary was chosen during the discrete-element modelling of CPT simulations. The

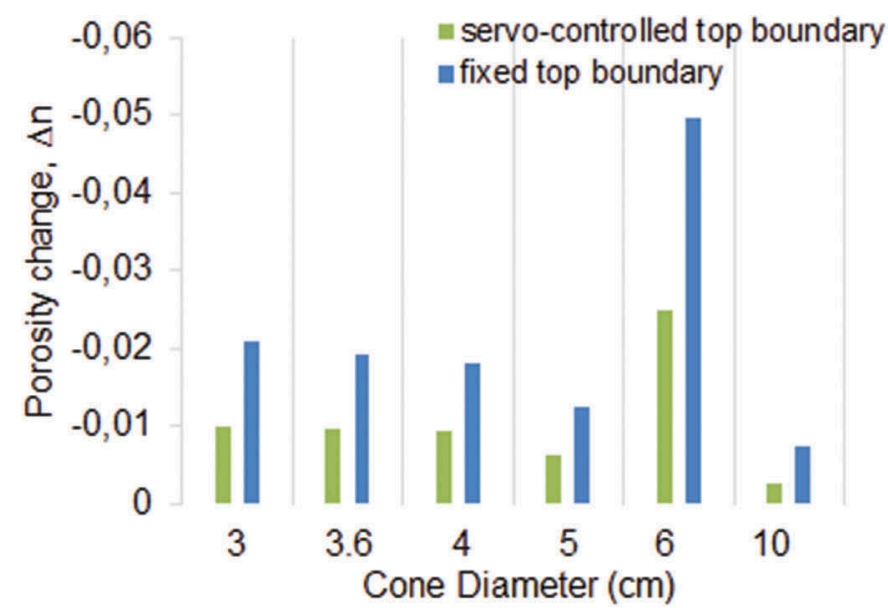

Figure 9. Estimation of top boundary condition: Initial porosity change after insertion of the cone to the discrete material at various cone diameters (particle size, $d=2 \mathrm{~cm}$ ). 
servo-controlled top boundary adjusted its position to maintain constant vertical stress.

After applying the servo-controlled top boundary to the discrete-element modelling of CPT simulations, the parametric study was conducted to obtain a maximum number of contacts between particles and $3.6-\mathrm{cm}$ diameter cone. The cone shaft that consisted of stiff walls had to always be in contact with at least a few particles at each side of the cone so that constant vertical-force readings could be obtained. Cones with six different diameters, from 3 to $10 \mathrm{~cm}$, were inserted into the 2$\mathrm{cm}$ diameter particle assembly (shown in Figure 8(a)) at a depth of $1 \mathrm{~m}$. Table 2 displays the number of particle contacts with the cone surface gathered from each test. The ratio of number of particle contacts with cone surface to cone diameter is defined as $R_{\mathrm{c}}$. The highest $R_{\mathrm{c}}$ was found to be 1.5 for the $6-\mathrm{cm}$ diameter cone inserted in the $2-\mathrm{cm}$ diameter particle assembly. This leads to the conclusion that with real dimensions of the cone (diameter of $3.6 \mathrm{~cm}$ ), the diameter of the discrete particles should be around $1.2 \mathrm{~cm}$, which is $1 / 3$ of the cone diameter.

3.3.1.2. Effect of discrete particle size on porosity. The most significant difference between experiment and simulation is the scaled particle size. If particle size was not scaled, the initial number of particles filling the box would increase by four orders of magnitude (Butlanska et al. 2010). The increase in particle number would increase the computation time. To determine the satisfying size of spherical grain with affordable computation time, a total of $24 \mathrm{CPT}$ simulations were conducted, into the discrete material shown in Figure 8 (a), up to 1-m depth. The servo-controlled top boundaries used in the simulations. The cone had an actual diameter of $3.6 \mathrm{~cm}$, used in the laboratory.

The raw cone-penetration resistance was obtained from the recorded vertical force at different depths to the cross-sectional area of the cone. The diameter of the particles was selected as $0.8,1.0,1.5$, and $2.0 \mathrm{~cm}$. A scaling factor $(S)$, which includes the diameter of the cone and the discrete particle, was incorporated into the raw $q_{c}$ value by the final equation given below:

$$
\begin{gathered}
\left(q_{\mathrm{c}}\right)_{\mathrm{raw}}=\frac{F_{\mathrm{y}}}{A_{\mathrm{c}} \cdot S} \\
S=\frac{2 \pi(0.5 D+d)}{d}
\end{gathered}
$$

Here, $F_{\mathrm{y}}$ is the force in $Y$ direction accumulated on the cone sides; $A_{\mathrm{c}}$ is the cross-sectional area of the cone (in this study, $10 \mathrm{~cm}^{2}$ ); $D$ is the diameter of the cone (in this study, $3.6 \mathrm{~cm}$ ); and $d$ is the diameter of the discrete particle. In two-dimensional simulations, we have collected $F_{\mathrm{y}}$ from two surfaces. The scaling factor $S$ takes into account three-dimensional geometry and assumes how many surfaces with given particles and cone dimensions should be calculated for reliable results. Then, raw penetration resistances were corrected for sample size effects by using the expression given by Jamiolkowski et al. (2003).

$$
q_{\mathrm{c}}=A\left(D_{\mathrm{r}}\right)^{\mathrm{B}}\left(q_{\mathrm{c}}\right)_{\mathrm{raw}}
$$

where $A$ and $B$ are coefficients that depend on $R_{\mathrm{d}}$. Butlanska et al. (2010) showed that;

$$
\begin{gathered}
A=9 \times 10^{-5}\left(R_{\mathrm{d}}\right)^{2.02} \\
B=-0.565 \ln \left(R_{\mathrm{d}}\right)+2.59
\end{gathered}
$$

The cone-penetration resistances, throughout the depth, were very noisy with large oscillations (exemplified in Figure 10(a)). This was due to the small ratio of cone diameter to particle size (Butlanska et al. 2014). Therefore, limit cone-penetration resistance, defined as $\left(q_{\mathrm{c}}\right)_{\text {limit }}$, was extracted from the raw cone-penetration resistance curves by using the fitting function proposed by Arrayo et al. (2011).

$$
q_{\mathrm{c}}=a\left(1-e^{-b h}\right)
$$

where $h$ is penetration depth, $a$ and $b$ are parameters of the fitting function. Parameter $a$ gives the asymptotic value of $q_{\mathrm{c}}$ and parameter $b$ is inversely related to the limit of shallow penetration. The application of this procedure is illustrated in Figure 10(a) for the initial porosity of 0.15 and particle diameter of $1 \mathrm{~cm} \mathrm{CPT-}$ DEM model.

Figure 10(b) shows the change in limit cone-penetration resistance with particle diameter in a range of initial porosities from 0.11 to 0.16 . It is clear from the figure that for particle diameters of 0.8 and $1.0 \mathrm{~cm}$ the $\left(q_{\mathrm{c}}\right)_{\text {limit }}$ values were very similar. This similarity might be caused by reaching the packing that gave a constant number of particles on both sides of the cone. Therefore, the maximum discrete particle diameter of $1 \mathrm{~cm}$ was used for penetration of cone $(D=3.6 \mathrm{~cm})$ into the large sample $\left(R_{\mathrm{d}}>19\right)$ that has constant stresses at top and side boundaries. This leads to the conclusion that for the simulation of CPTs at largesized granular material (servo-controlled top and side walls), discrete particles with a diameter 3.6 times smaller than the diameter of the cone can be used accurately at the two-dimensional environment.

\subsubsection{Test series III}

CPT simulation series III was performed to (1) calibrate the initial porosity of the model by using the results of 


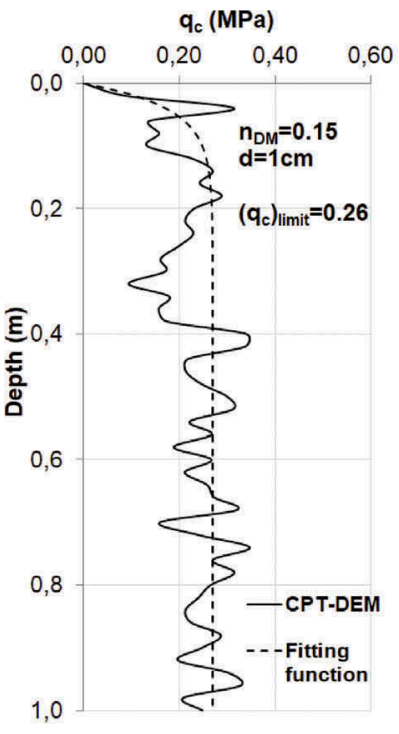

(a)

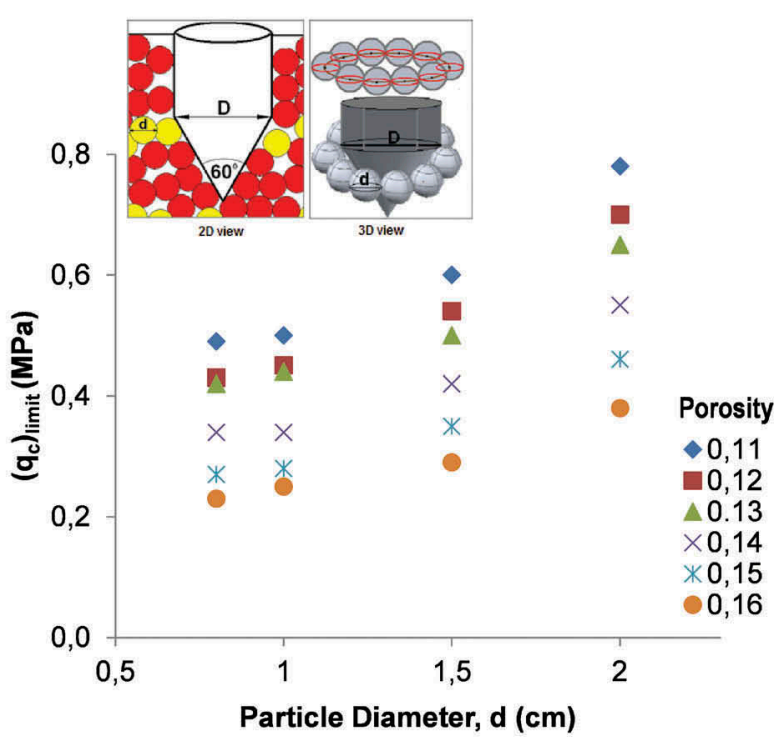

(b)

Figure 10. (a) Application procedure of fitting function to extract $\left(q_{c}\right)_{\text {limit }}$ for initial porosity of 0.15 and particle diameter of $1 \mathrm{~cm}$, and (b) effect of particle diameter on limit cone-penetration resistance at different initial porosities (cone size, $D=3.6 \mathrm{~cm}$ ).

the CPTs conducted in the laboratory, and (2) investigate the limit porosity of the model for realistic penetration results. The schematic view of the DEM-CPT system model including the cone, sample, and boundary conditions, used in this test series, is shown in Figure 11. The height of the sample built in the DEM simulations

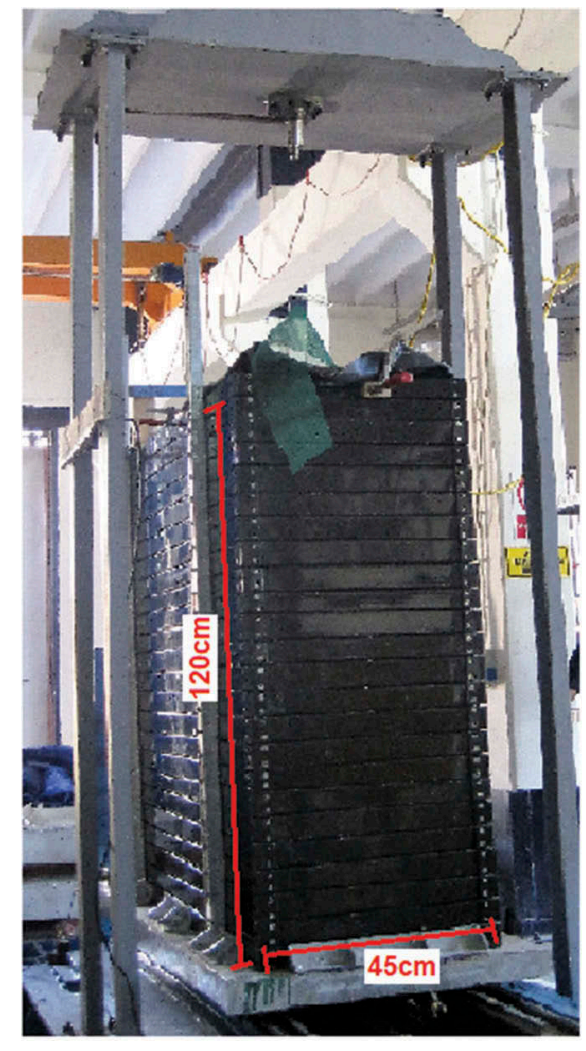

CPT Test

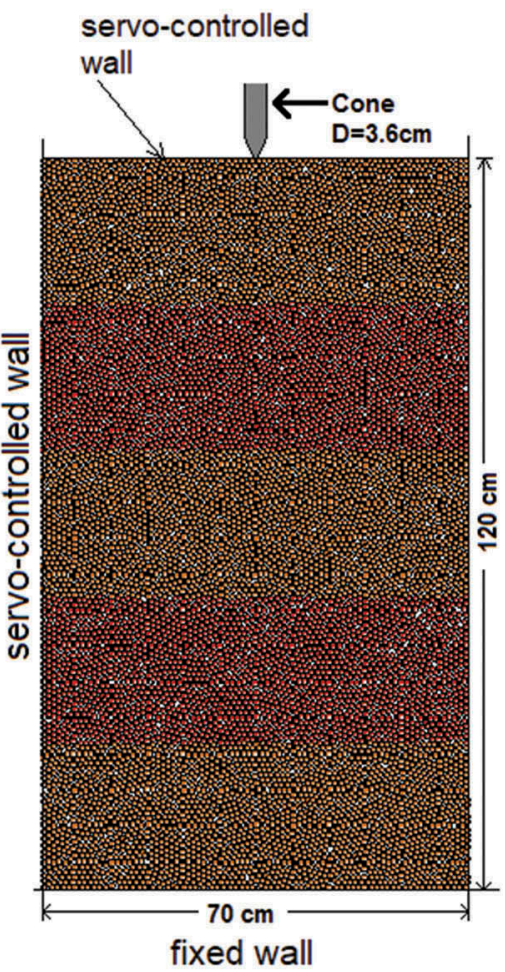

DEM Simulation

Figure 11. Geometrical characteristics of physical CPT and DEM simulation. 
was set to $120 \mathrm{~cm}$ and the width set to $70 \mathrm{~cm}$. The actual initial dimensions of the soil sample were $120 \mathrm{~cm}$ by $45 \mathrm{~cm}$ (height $\times$ width). The ratio of particle diameter to sample width $(70 \mathrm{~cm})$ was chosen as $1 / 70$, which is close to the biaxial test ratio (1/50). The geometry of the penetrometer built in the DEM simulations was same as the one used in the physical CPT (cone diameter of $3.6 \mathrm{~cm})$.

To compare the penetration resistance obtained from the CPT-DEM model and tests conducted in the laboratory, the discrete material needed to be fully saturated. A fixed coarse-grid fluid flow (SIMPLE) scheme similar to that developed by Patankar (1980) incorporated into the DEM model to support coupled fluid-particle simulations. As shown in Figure 12(a), extra fluid cells were created outside the walls of the model. Their function was to reflect the boundary conditions of the model. To maintain numerical stability, the zero-pressure boundary was selected at the top of the model box, and slip-wall boundaries were selected at bottom and side boundaries. For a slipwall boundary, the fluid velocity parallel to the wall surface was non-zero. A total number of finite grids were chosen to be 1200 , including 40 grids in the $X$ direction and 30 grids in the $Y$ direction. The time step for the SIMPLE scheme was set to $2 \times 10^{-3} \mathrm{~s}$.

\subsubsection{Calibration of DEM-CPT model initial poros-} ity with physical CPTs. Figure 12(b) shows the schematic view of cone penetration into the discrete material. Different contour colours were used to observe movements of particles during cone penetration. A total of eight assemblies of spherical particles with different initial porosities from 0.09 to 0.16 were prepared. With regard to the previous findings of Utili and Nova (2008), the limit two-dimensional porosity of 0.09 and 0.16 was employed as the tightest and loosest assembly, respectively. The assembly representing the micromechanical model of saturated sand with specified above porosity range consisted of 8960 to 9700 particles.

For eight different initial porosities of discrete material, $n_{\mathrm{DM}}$ from 0.09 to 0.16 , the $\left(q_{c}\right)_{\text {limit }}$ values from CPT-DEM simulations were determined. These $\left(q_{\mathrm{c}}\right)_{\text {limit }}$ values substituted into Equation (2) to obtain the corresponding porosity of tested sand.

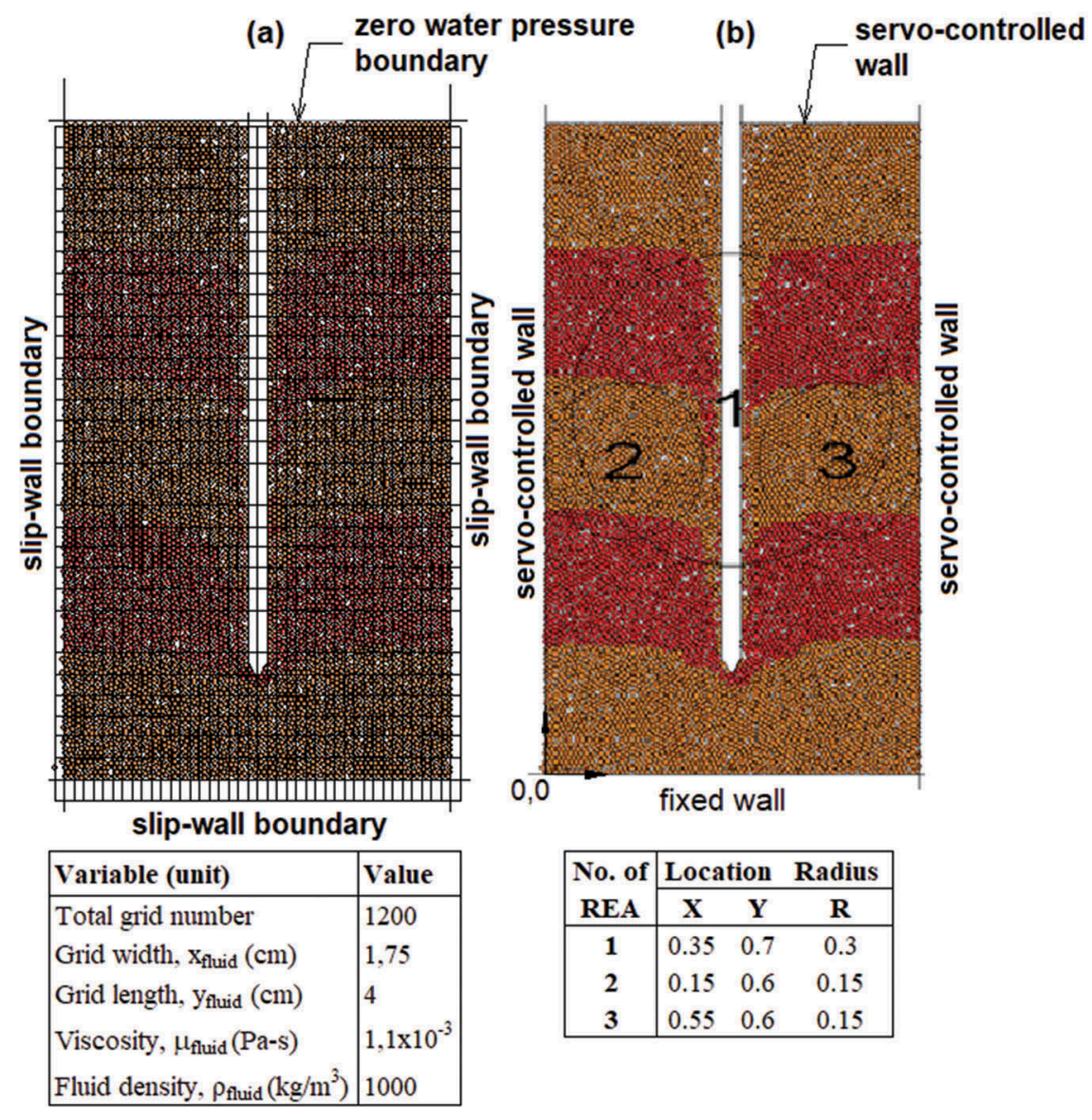

Figure 12. (a) Fixed coarse-grid fluid flow (SIMPLE) scheme and finite grids implemented in the DEM modelling, and (b) DEM-CPT model after cone penetration into the discrete material and location of REAs inside the box. 


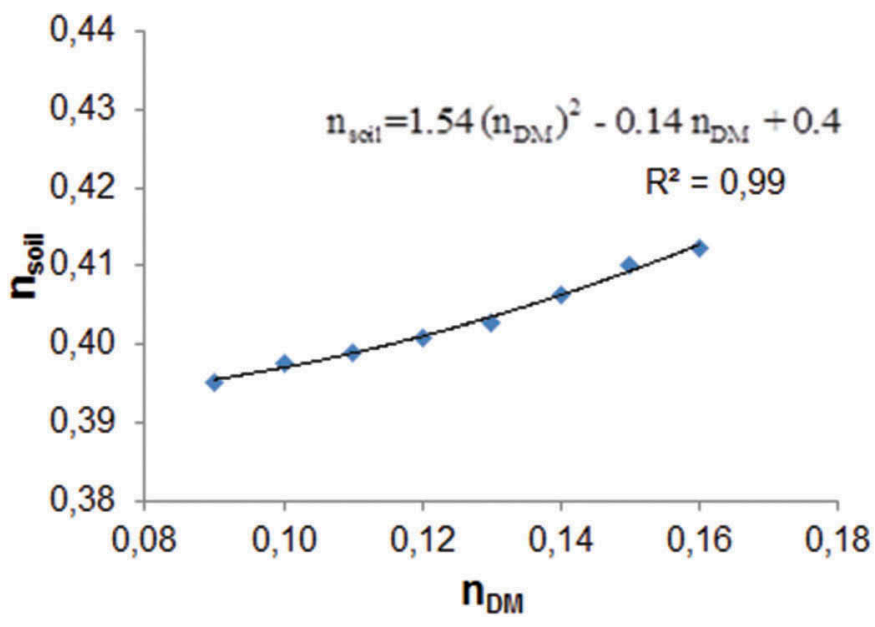

Figure 13. Relationship between initial porosity of tested granular material and discrete material.

$$
n_{\text {soil }}=1.54\left(n_{\mathrm{DM}}\right)^{2}-0.14 n_{\mathrm{DM}}+0.4
$$

Figure 13 shows the relationship between the porosity of tested soil and the discrete material. As it can be seen from the figure, a significant difference was observed at porosity between the two-dimensional uniform circle packing of discrete particles and the soils used in the laboratory experiments. This outcome is satisfactory when porosity values, in two- and threedimensional simulations, reported in the literature were considered. Deresiewicz (1958) proved that the closest of regular packings of uniform spheres in threedimensional simulations has a porosity of 0.2595 while the same assembly in two-dimension has a porosity of 0.0931. Calvetti and Nova (2005) similarly found that porosity is far smaller in two-dimension than in threedimension.

\subsubsection{DEM-CPT model limit porosity for accurate} penetration results. Once the initial porosity in the two-dimensional DEM-CPT model was calibrated by using the CPTs conducted in the laboratory, we investigated the limit porosity of the numerical model for accurate penetration results. As shown in Figure 12(b), three REAs were positioned inside the model. The REA-2 and REA-3, which had radii of $15 \mathrm{~cm}$, were positioned at two sides of the cone in the middle depth of the box. The REA-1, which had a radius of $30 \mathrm{~cm}$, was created at the centre of the discrete model. In order to check whether the sizes and locations of REAs were representative, the porosities obtained from REA-2 and REA-3 were compared with REA-1. Although REA-1 gives wiser observation perspective before the cone penetration, REA-2 and REA-3 enabled us to observe changes which occurred in the discrete element after the CPTs. Therefore, the porosity before and after cone penetration was obtained by averaging the porosities from REA-2 and REA-3.

A total of eight assemblies of spherical particles with different initial porosities $\left(n_{\mathrm{DM}}\right)$ from 0.09 to 0.16 were prepared. At each of these discrete particle packings, the porosity before and after penetrating the cone into the discrete material was calculated and is presented in Figure 14(a). At each initial porosity of the discrete material, the measured porosity was expected to decrease due to cone insertion. However, for the $n_{\mathrm{DM}}$ smaller than 0.11 , an increase in porosity was observed after cone insertion. This might be due to the particlepacking density that can be described by $\mathrm{CN}$ in soil micromechanics. Simply, the $\mathrm{CN}$ is the average number of active contacts per single particle over the specified area (McDowell et al. 1996). Although $\mathrm{CN}$ is an important microparameter, it can also be viewed as a macroparameter by REA. Nevertheless, little information is available for soil assemblies because of the difficulty of investigating them experimentally (Göncü et al. 2010). In this study, the CNs were determined from REA-2 and REA- 3 by using the empirical relationship given by Thornton (2000):

$$
\mathrm{CN}=\frac{2 N_{\mathrm{c}}-N_{1}}{N_{\mathrm{p}}-N_{\mathrm{o}}-N_{1}}
$$

Here, $N_{c}$ is the number of contacts, and $N_{p}$ is the number of particles. $N_{\mathrm{o}}$, and $N_{1}$ are referred as the number of floating particles with zero and one contact, respectively (O'Sullivan 2011). Thornton (2000) proposed this correlation based on the fact that particles that only have one or zero contacts do not participate in the stress transmission. The average $\mathrm{CNs}$ obtained from REA-2 and REA-3 before and after cone penetration at each deposit with given initial porosity varying 
(a)

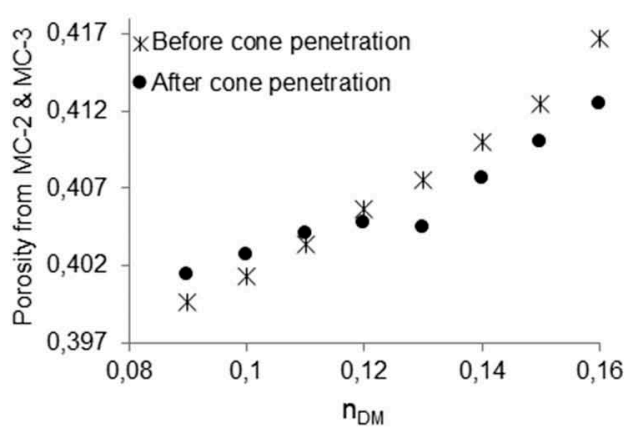

(b)

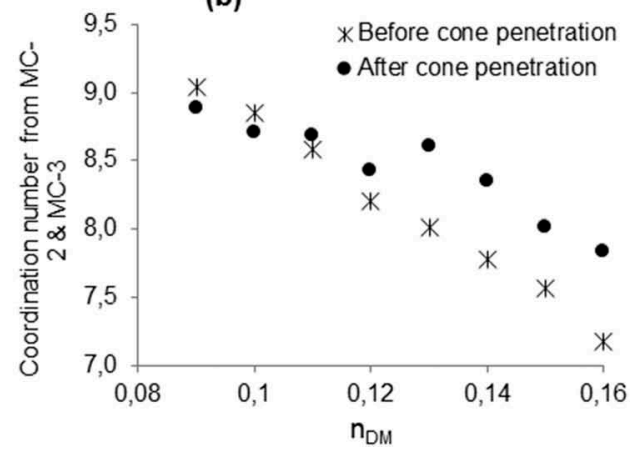

Figure 14. For each assembly, average (a) porosity and (b) CN from MC-2 and MC-3 inside the box, before and after conepenetration simulations.

from 0.09 to 0.16 are presented in Figure 14(b). As the REAs (REA-2 and REA-3) were located in the vicinity of the cone, the $\mathrm{CN}$ was supposed to increase after cone penetration. However, it occurred that for the porosities smaller than 0.11 (dense particle packing), the average $\mathrm{CN}$ after cone penetration was slightly smaller than before cone penetration. The deposits with porosity denser than 0.11 in the DEM showed unrealistic results in both porosity and $\mathrm{CN}$.

A number of different expressions relating the $\mathrm{CN}$ to the porosity have been proposed based on experimental studies on spheres (e.g. Oda 1977). A unique correlation between $\mathrm{CN}$ and porosity may only exist for regular packing of rigid and equal-sized spheres, and accordingly, its application to real soil and even DEM packing is limited, as it will clearly depend on the particle morphology, both shape and surface roughness, and the particle size distribution. In this study, the correlation between the average $\mathrm{CN}$ and porosity measured from REA-2 and REA-3 before and after cone penetration is shown in Figure 15. The trend observed indicates an increase in the number of contacts as porosity decreases, and the relationship obtained is $n=0.5 \mathrm{e}^{-0.02 \mathrm{CN}}$ with a regression coefficient of 0.95 . Fonseca (2011) reported a similar trend with a regression coefficient of 0.88 . For real sand specimens, Hasan and Alshibli (2010) proposed a similar trend with a rather scattered plot with a regression coefficient of 0.68 .

\section{Comparison of DEM-CPT model and physical CPT results}

To gain further insight into the limit porosity that can be used in the numerical model, we performed additional CPT simulations. Figure 16 shows the comparison of cone-penetration resistance obtained in the laboratory and numerical simulations for the range of relative densities starting from $45 \%, 50 \%, 60 \%$, and $65 \%$, respectively. For $45 \%$ relative density, the initial porosity used in the numerical simulations was around 0.15 . For $65 \%$ relative density, the initial porosity used in the numerical simulations was around 0.11 .

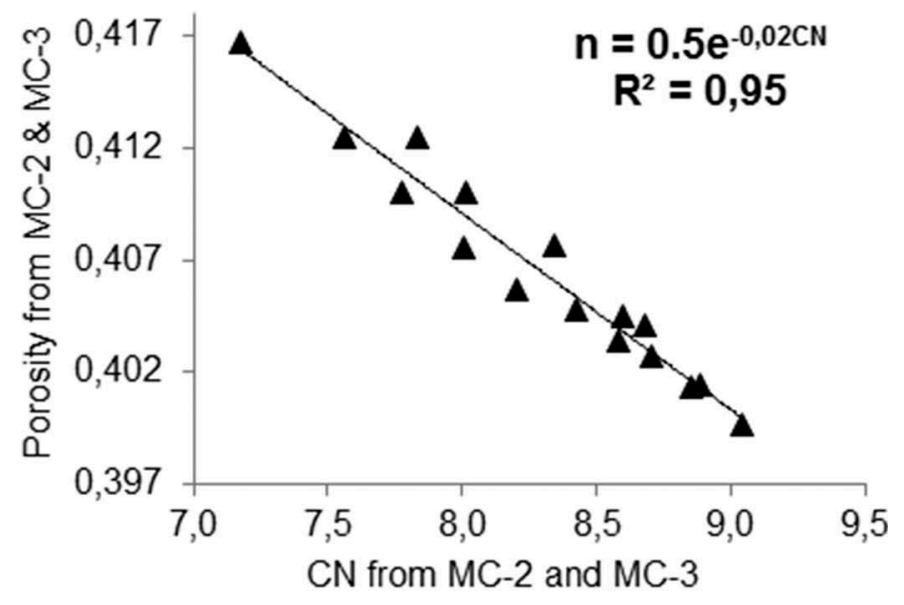

Figure 15. Relationship between $\mathrm{CN}$ and porosity from MC-2 and MC-3, before and after cone penetration. 


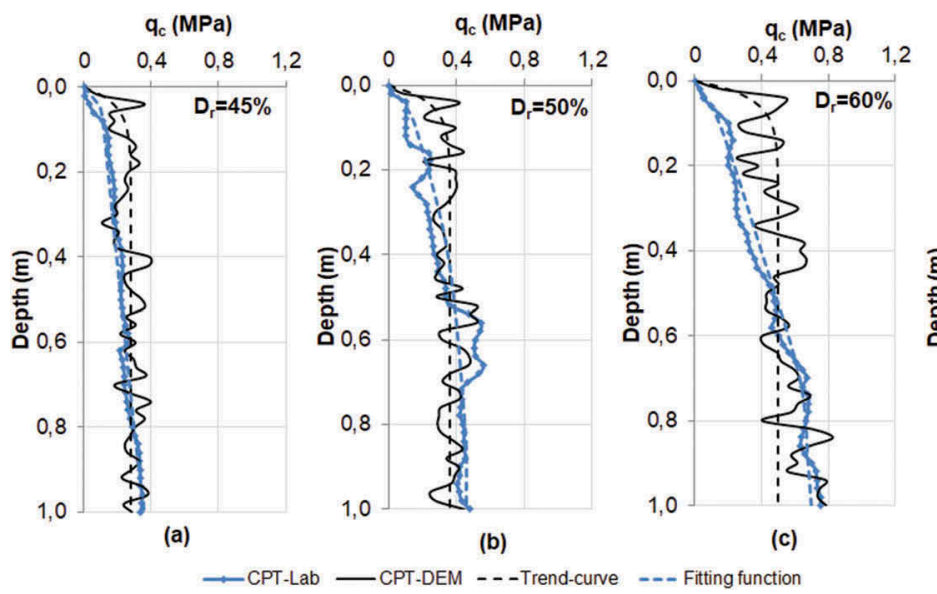

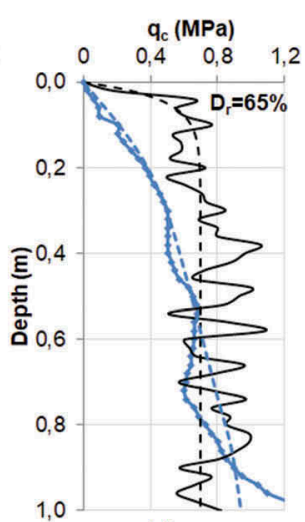

(d)

Figure 16. Comparison of cone-penetration resistance obtained throughout the depth from CPT-DEM simulations and laboratory tests for relative density of (a) $45 \%$, (b) $50 \%$, (c) $60 \%$, and (d) $65 \%$.

The results show that the cone-penetration resistance was not constant throughout the depth both in CPTs performed in the laboratory and the DEM model. In the DEM model, $q_{c}$ values were prone to be affected by the history of the packing. In the laboratory, the method of soil preparation was the main factor that affected the uniformity and penetration resistance of sand deposited along the depth. We also observed that cone-penetration resistance from CPTDEM modelling showed more fluctuations than laboratory CPTs. This was due to a number of contacts between particles and cone since the effects of particle size are more pronounced. Based on the studies of Butlanska et al. (2010), as the particles per cone diameter increases, the penetration curve clearly smoothens. For soil deposits having a relative density from $45 \%$ to $60 \%, q_{c}$ values were steady and almost in good agreement throughout the depth. However, for the relative density of $65 \%$ (denser packing), we observed that the penetration resistance did not reach the limit value at $1-\mathrm{m}$ depth. The above simulations showed that the initial porosity of 0.11 (representing the relative density of real soil at around 65\%) can be a minimum threshold porosity value that can be used in twodimensional cone-penetration simulations due to particle packing.

It was observed that in dense assemblies $\left(\mathrm{n}_{\mathrm{DM}}<\right.$ 0.11 ) when cones were inserted into the discrete particles in two-dimensional deposits, the laws that govern the calculation cycles were not properly updating the location of particles, wall positions, and the set of contacts between particles. We observed that some particles were moving throughout the boundaries. It can be concluded that, when modelling the performance of such CPT systems, the interaction of the two-dimensional discrete material with rigid walls was not precise or efficient. Due to the geometry of the CPT model, where outer boundary walls had significantly greater dimensions than the cone, in assemblies with porosities less than 0.11 , the particles were moving through outer boundary walls.

\section{Conclusions}

The CPT deformation effects are complicated. This is why continuous remeshing and perfect constitutive modelling are needed during simulation of cone penetration at FEM or FDM models. The DEM avoids the usage of a constitutive model. However, it introduces additional unknowns to the micromechanical parameters, such as discrete material packing (porosity), and $\mathrm{CN}$. In this paper, we performed two-dimensional CPT-DEM simulations to investigate the top boundary conditions, discrete particle size, and limit initial porosity for reliable cone-penetration simulation results. To do this investigation, first, calibration of the elastic and plastic microproperties of discrete material was performed by comparing the physical and numerical triaxial test results. The following results can be summarized as follows:

(1) The cone-penetration resistance values obtained from the simulations affected by the boundary conditions. It was found that the fixed top boundary caused large porosity reduction and discrete particles randomly move after they contacted the cone. Therefore, it was decided to use servo-controlled top and side boundaries for realistic CPT results.

(2) The cone-penetration resistance values were scaled by proposed scaling factor, which takes into account three-dimensional geometry and assumes how many surfaces with given particles 
and cone dimensions should be calculated for reliable results. To the authors' knowledge, the validity of the scaling laws incorporated into numerical analyses has not been checked in a wider scope of soil materials.

(3) The CPT simulations can be affected by the sample/cone size. To eliminate the sample size affects the cone-penetration resistance values were corrected by a correction number which is a function of relative density and $R_{\mathrm{d}}$ value (ratio of sample size to cone size).

(4) For the simulation of CPTs at large-sized granular material (servo-controlled top and side walls), discrete particles with a diameter 3.6 times smaller than the diameter of the cone can be used accurately at the two-dimensional environment.

(5) After insertion of the cone into the discrete material, the soil response in different packing conditions was investigated to define the limit value of porosity. Consequently, the lower-limit value of initial porosity was found to be 0.11 . This limit porosity was verified by comparison of cone-penetration resistance obtained in the laboratory and numerical simulations for the range of relative densities.

The above-mentioned results show that a balance can be reached between realistic simulation and efficiency in computation, when proper boundary conditions, cone size, discrete particle size, and packing are used. DEM model can be a powerful tool to enrich the conventional physical CPTs and can be widely and successfully applied both in scientific research and engineering practice. We note that in this study, several aspects of the behaviour of granular materials, such as anisotropy, elastic deformability, particle crushing, and plastic deformability, could also help to better understand the soil response due to cone insertion. However, these have not yet been investigated.

\section{Disclosure statement}

No potential conflict of interest was reported by the authors.

\section{Funding}

This study was funded by TUBITAK (grant number: 111M435).

\section{References}

Ahmadi, M.M., Byrne, P.M., and Campanella, R.G., 2005. Cone tip resistance in sand: modeling, verification and applications. Canadian Geotechnical Journal, 42, 977993. doi:10.1139/t05-030

Arroyo, M., et al., 2011. Cone penetration tests in a virtual calibration chamber. Géotechnique, 61 (6), 525-531. doi:10.1680/geot.9.P.067

Bakunowicz, P., 2014. Discrete element modelling of CPT using shaking table tests in sands. (MS thesis). Department of Civil Engineering, Izmir Institute of Technology, 143.

Bakunowicz, P. and Ecemis, N., 2014. Validation of porosity in 2D-DEM CPT model using large scale shaking table tests in saturated sands" In: 14th International conference of the International Association for Computer Methods and Advances in Geomechanics, Japan

Baligh, M.M., 1975. Theory of deep static cone penetration resistance. Cambridge, MA: Dept. of Civil and Env. Eng., MIT, Rep. No. R75-76.

Baligh, M.M., 1985. Strain path method. Journal of Geotechnical Engineering. ASCE, 111 (9), 1108-1136.

Bienen, B., Henke, S., and Pucker, T., 2011. Numerical study of the bearing behavior of circular footings penetrating into sand. In: Proceedings of the 13th international conference of the International Association for Computer Methods and Advances in Geomechanics (IACMAG), Melbourne, Australia. 939-944.

Bolton, M.D. and Gui, M.W., 1993. The study of relative density and boundary effects for cone penetration tests in centrifuge. Department of Engineering, Cambridge University, Research report: CUED/D-SOILS/TR256.

Butlanska, J., et al., 2014. Multi-scale analysis of cone penetration test (CPT) in a virtual calibration chamber. Canada Geotechnical Journal, 51, 51-66. doi:10.1139/cgj2012-0476

Butlanska, J., Arroyo, M., and Gens, A., 2010. Size effects on a virtual calibration chamber. In: 7 th European conference on numerical methods in geotechnical engineering, NUMGE, Trondheim, 225-230.

Butlanska, J., Arroyo, M., and Gens, A., 2009. Homogeneity and symmetry in DEM models of cone penetration. In: M. Nakagawa and S. Luding eds. Proceedings of AIP conference on powders and grains 2009, 1145, 425429.

Calvetti, F. and Nova, R., 2005. Micro-macro relationship from DEM simulated element and in-situ tests. Powders and Grains, I, 1292-1299.

Ciantia, M.O., et al., 2016. Numerical investigation of the incremental behavior of crushable granular soils. International Journal for Numerical and Analytical Methods in Geomechanics, 40 (13), 1773-1798. doi:10.1002/nag.2503

Cundall, P.A. and Strack, O.D.L., 1979. A discrete numerical model for granular assemblies. Géotechnique, 29 (1), $47-$ 65. doi:10.1680/geot.1979.29.1.47

Deresiewicz, H., 1958. Mechanics of granular matter. Advances in Applied Mechanics, 5, 233-306. doi:10.1016/ S0065-2156(08)70021-8

Durgunoglu, H.T. and Mitchell, J.K., 1975a. Static penetration resistance of soils: I. Analysis. In: Proceedings of the conference on in-situ measurement of soil properties, $\mathrm{N}$. Y.: ASCE, 1, 151-171.

Durgunoglu, H.T. and Mitchell, J.K., 1975b. Static penetration resistance of soils: II. Evaluation of theory and implications for 
practice. In: Proceedings of the conference on in-situ measurement of soil properties, N.Y.: ASCE, Vol. 1, 172-189.

Ecemis, N., 2013. Simulation of seismic liquefaction: 1-g model testing system and shaking table tests. European Journal of Environmental and Civil Engineering, 17 (10), 899-919. doi:10.1080/19648189.2013.833140

Ecemis, N., Demirci, H.E., and Karaman, M., 2015. Influence of consolidation properties on the cyclic re-liquefaction potential of sands. Bulletin of Earthquake Engineering, 13 (6), 1655-1673. doi:10.1007/s10518-014-9677-y

Fonseca, J., 2011. The evolution of morphology and fabric of a sand during shearing. ( $\mathrm{PhD}$ thesis). Department of Civil and Environmental Engineering, Imperial College, London.

Geng, Y., 2010. Discrete element modelling of cavity expansion in granular materials. (PhD Thesis). University of Nottingham, Nottingham, UK.

Ghionna, V. and Jamiolkowski, M., 1991. A critical appraisal of calibration chamber testing of sands. In: A. B. Huang, ed. Proceedings of 1st international symposium on calibration chamber testing (ISOCCT1). New York, NY: Elsevier Applied Science, 13-39.

Göncü, F., Durán, O., and Luding, S., 2010. Constitutive relations for the isotropic deformation of frictionless packings of polydisperse spheres. Comptes Rendus Mécanique, 338 (10-11), 570-586. doi:10.1016/j.crme.2010.10.004

Hasan, A. and Alshibli, K., 2010. Experimental assessment of $3 \mathrm{D}$ particle-toparticle interaction within sheared sand using synchrotron microtomography. Géotechnique, 60 (5), 369-379. doi:10.1680/geot.2010.60.5.369

Houlsby, G.T. and Hitchman, R., 1988. Calibration chamber tests of a cone penetrometer in sand. Géotechnique, 38, 575-587. doi:10.1680/geot.1988.38.4.575

Houlsby, G.T., Wheeler, A.A., and Norbury, J., 1985. Analysis of undrained cone penetration as a steady flow problem". In: Proceedings of 5th international conference on numerical methods in Geomech, Rotterdam, The Netherlands: A. A. Balkema, Vol. 4, 1767-1773.

Huang, A.B. and Ma, M.Y., 1994. An analytical study of cone penetration tests in granular material. Canada Geotechnical Journal, 31 (1), 91-103. doi:10.1139/t94-010

Itasca Consulting Group: PFC2D, 2008. Version 4.0 manual. 3rd ed. Minesota: Itasca Consulting Group, Inc.

Jamiolkowski, M., et al., 1985. New developments in field and laboratory testing of soils. State-of-the art report. In: Proceedings of the 11th international conference on soil mechanics and foundation engineering, San Francisco, 57-153.

Jamiolkowski, M., Lo Presti, D.C.F., and Manassero, M., 2003. Evaluation of relative density and shear strength of sands from CPT and DMT. In Soil behavior and soft ground construction. ASCE Geotechnical Special Publication, 119, 201-238.

Janbu, N. and Senneset, K., 1974. Effective stress interpretation of in-situ static cone penetration tests. In: Proceedings of 1st European symposium on penetration testing, Vol. 2, 181-193.

Jiang, M.J., Yu, H.S., and Harris, D., 2006. Discrete element modelling of deep penetration in granular soils. International Journal for Numerical and Analytical Methods in Geomechanics, 30 (4), 335-361. doi:10.1002/nag.473

Kinloch, H. and O'Sullivan, C., 2007. A micro-mechanical study of the influence of penetrometer geometry on failure mechanisms in granular soils. Geo-Denver: New Peaks in Geotechnics, GSP 173 Advances in Measurement and Modeling of Soil Behavior.

Koloski, J.W., Schwarz, S.D., and Tubbs, D.W., 1989. "Geotechnical properties of geologic materials". In: Engineering Geology in Washington, Vol. 1, 19-24. Olympia, WA: Washington Dept. of Natural Resources.

Kruyt, N.P., 1993. Towards micro-mechanical constitutive relations for granular materials. In: Proceedings of modern approaches to plasticity, Balkema, 147-178.

Lambe, T.W. and Whitman, R.V., 1969. Soil mechanics. New York: Wiley.

Lin, J. and Wu, W., 2012. Numerical study of miniature penetrometer in granular material by discrete element method. Philosophical Magazine, 92 (28-30), 3474-3482. doi:10.1080/14786435.2012.706373

Lunne, T., Robertson, P.K., and Powell, J.J.M., 1997. Cone penetration testing in geotechnical practice. In: Blackie Academic/Chapman-Hall Publishers. New York: EF Spon/ Routledge Publishers, 312.

Ma, M.Y., 1994. A numerical study of cone penetration test in granular assemblies. (PhD Thesis). Clarkson University.

Mayne, P.W., 2007. Cone penetration testing: state of practice. Washington, DC: Transportation Research Board, No. 20-05, NCHRP Report.

McDowell, G.R., Bolton, M., and Robertson, D., 1996. The fractal crushing of granular materials. Journal of the Mechanics and Physics of Solids, 44, 2079-2101. doi:10.1016/S0022-5096(96)00058-0

McDowell, G.R., Falagush, O., and Yu, H.S., 2012. A particle refinement method for simulating DEM of cone penetration testing in granular materials. Géotechnique Letters, 2 (July-September), 141-147. doi:10.1680/geolett.12.00036

Meyerhof, E., 1961. The ultimate bearing capacity of wedgeshaped foundations. In: Proceedings of 5th international conference on soil mechanics and foundation engineering, Vol. 2, 103-109.

Mitchell, J.K., et al., 1999. Effects of placement method on geotechnical behavior of hydraulic fill sands. Journal of Geotechnical and Geoenvironmental Engineering, 125 (10), 832-846. doi:10.1061/(ASCE)1090-0241(1999)125:10(832)

Oda, M., 1977. Co-ordination number and its relation to shear strength of granular material. Soils and Foundations, 17 (2), 29-42. doi:10.3208/sandf1972.17.2_29

O'Sullivan, C., 2011. Particle-based discrete element modeling: geomechanics perspective. International Journal of Geomechanics, 11 (6), 449-464. doi: 10.1061/(ASCE) GM.1943-5622.0000024

Parkin, A.K. and Lunne, T., 1982. Boundary effects in the laboratory calibration of a cone penetrometer for sand. In: Proceedings of the 2nd European symposium on penetration testing. ESOPT-II Amsterdam 2:761:768.

Patankar, S.V., 1980. Numerical heat transfer and fluid flow. Washington, D.C: Hemisphere Publishing.

Phillips, R. and Valsangkar, A.J., 1987. An experimental investigation of factors affecting penetration resistance in granular soils in centrifuge modelling. UK: Cambridge University, Technical Report No CUED/D-Soils TR210.

Poulos, S.J. and Hed, A., 1973. Density measurements in a hydraulic fill. Evaluation of relative density and its role in geotechnical projects involving cohesionless soils. ASTM STP, 523, 402-424. 
Renzi, R., et al., 1994. Cone penetration tests in the centrifuge: experience of five laboratories. In: Proceedings of international conference centrifuge 94, Singapore, 77-82.

Robertson, P.K. and Campanella, R.G., 1983. Interpretation of cone penetration tests. Part I: sand. Canada Geotech Journal, 20 (4), 718-733. doi:10.1139/t83-078

Salgado, R., Mitchell, J.K., and Jamiolkowski, M., 1997. Cavity expansion and penetration resistance in sand. Journal of Geotechnical and Geoenvironmental Engineering, 123 (4), 344-354. doi:10.1061/(ASCE)10900241(1997)123:4(344)

Sitharam, T.G. and Nimbkar, M.S., 2000. Micromechanical modelling of granular materials: effect of particle size and gradation. Geotechnical and Geological Engineering, 18 (2), 91-117. doi:10.1023/A:1008982027109

Susila, E. and Hryciw, R.D., 2003. Large displacement FEM modelling of the cone penetration test in normally consolidated sand. International Journal Numerical Analytical Meth Geomechanics, 27 (7), 585-602. doi:10.1002/nag.287

Teh, C.I. and Houlsby, G.T., 1991. An analytical study of the cone penetration test in clay. LondonGeotechnique, U.K., 41 (1), 17-34.

Thevanayagam, S., et al., 2009. Laminar box system for 1-g physical modeling of liquefaction and lateral spreading. Journal ASTM Geotechnical Testing, 32 (5), 438-449.

Thornton, C., 2000. Numerical simulations of deviatoric shear deformation of granular media. Géotechnique, 50 (1), 43-53. doi: 10.1680/geot.2000.50.1.43

Ting, J.M., et al., 1989. Discrete numerical model for soil mechanics. Journal of Geotechnical Engineering, 115
(3), 379-398. doi:10.1061/(ASCE)0733-9410(1989) 115:3(379)

Utili, S. and Nova, R., 2008. DEM analysis of bonded granular geomaterials. International Journal Numerical Analysis Methods Geomechanics, 32, 1997-2031. doi:10.1002/nag.v32:17

Vaid, Y.P. and Sivathayalan, S., 2000. Fundamental factors affecting liquefaction susceptibility of sands. Canadian Geotechnical Journal, 37 (3), 592-606. doi:10.1139/t00040

Vermeer, P.A., et al., 2001. Continuous and discontinuous modelling of cohesive frictional materials. Berlin: Springer.

Vesic, A.S., 1972. Expansion of cavities in infinite soil mass. Journal of Soil Mechanics and Foundations Div. ASCE, 98 (3), 265-290.

Whitman, R.V., 1970. Hydraulic fills to support structural loads. Journal Soil Mechanisms and Foundation Div, 96 (SM1), 23-47.

Whittle, A.J., 1992. Constitutive modeling for deep penetration problems in clay. Proceedings of 3 rd internatinal conference on computational plasticity. Fundamentals and applications, 2, 883-894.

Wood, F.M., Yamamuro, J.A., and Lade, P.V., 2008. Effect of depositional method on the undrained response of silty sand. Canadian Geotechnical Journal, 45, 1525-1537. doi:10.1139/T08-079

Yu, H.S. and Mitchell, J.K., 1998. Analysis of cone resistance: review of methods. Journal of Geotechnical and Geoenvironmental Engineering, 124, 140-149. doi:10.1061/(ASCE)1090-0241(1998)124:2(140) 